\title{
Airborne and Ground-Based Measurements Using a High-Performance Raman Lidar
}

\author{
David N. Whiteman, ${ }^{a}$ Kurt Rush, ${ }^{a}$ SCOtt Rabenhorst, ${ }^{\mathrm{b}}$ WAYne Welch, ${ }^{\mathrm{c}}$ MARtin Cadirola, ${ }^{\mathrm{d}}$

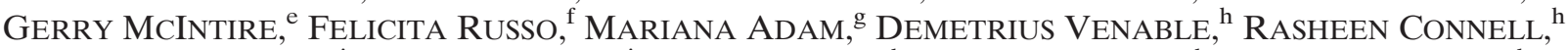

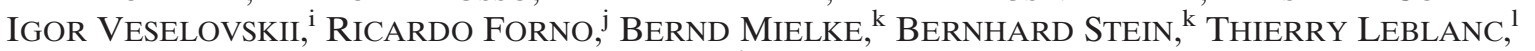 \\ STUART MCDERMID, ${ }^{1}$ AND HOLGER VÖMEL ${ }^{\mathrm{m}}$ \\ ${ }^{\mathrm{a}}$ NASA GSFC, Greenbelt, Maryland \\ ${ }^{\mathrm{b}}$ University of Maryland, College Park, College Park, Maryland \\ ${ }^{\mathrm{c}}$ Welch Mechanical Designs, Belcamp, Maryland \\ ${ }^{\mathrm{d}}$ Ecotronics, LLC, Clarksburg, Maryland \\ ${ }^{\mathrm{e}} S G T$, Lanham, Maryland \\ ${ }^{\mathrm{f}} \mathrm{CNR}$, Potenza, Italy \\ ${ }^{\mathrm{g}}$ European Commission-JRC, Ispra, Italy \\ ${ }^{\mathrm{h}}$ Howard University, Washington, D.C. \\ ${ }^{\mathrm{i}}$ University of Maryland, Baltimore County, Baltimore, Maryland \\ ${ }^{\mathrm{j}}$ Universidad Mayor de San Andres, La Paz, Bolivia \\ ${ }^{\mathrm{k}}$ Licel, Berlin, Germany \\ ${ }^{1}$ Jet Propulsion Laboratory, California Institute of Technology, Table Mountain Facility, Table Mountain, California \\ ${ }^{\mathrm{m}}$ Lindenberg Observatory, Lindenberg, Germany
}

(Manuscript received 17 September 2009, in final form 3 June 2010)

\begin{abstract}
A high-performance Raman lidar operating in the UV portion of the spectrum has been used to acquire, for the first time using a single lidar, simultaneous airborne profiles of the water vapor mixing ratio, aerosol backscatter, aerosol extinction, aerosol depolarization and research mode measurements of cloud liquid water, cloud droplet radius, and number density. The Raman Airborne Spectroscopic Lidar (RASL) system was installed in a Beechcraft King Air B200 aircraft and was flown over the mid-Atlantic United States during JulyAugust 2007 at altitudes ranging between 5 and $8 \mathrm{~km}$. During these flights, despite suboptimal laser performance and subaperture use of the telescope, all RASL measurement expectations were met, except that of aerosol extinction. Following the Water Vapor Validation Experiment-Satellite/Sondes (WAVES_2007) field campaign in the summer of 2007, RASL was installed in a mobile trailer for groundbased use during the Measurements of Humidity and Validation Experiment (MOHAVE-II) field campaign held during October 2007 at the Jet Propulsion Laboratory's Table Mountain Facility in southern California. This ground-based configuration of the lidar hardware is called Atmospheric Lidar for Validation, Interagency Collaboration and Education (ALVICE). During the MOHAVE-II field campaign, during which only nighttime measurements were made, ALVICE demonstrated significant sensitivity to lower-stratospheric water vapor. Numerical simulation and comparisons with a cryogenic frost-point hygrometer are used to demonstrate that a system with the performance characteristics of RASL-ALVICE should indeed be able to quantify water vapor well into the lower stratosphere with extended averaging from an elevated location like Table Mountain. The same design considerations that optimize Raman lidar for airborne use on a small research aircraft are, therefore, shown to yield significant dividends in the quantification of lower-stratospheric water vapor. The MOHAVE-II measurements, along with numerical simulation, were used to determine that the likely reason for the suboptimal airborne aerosol extinction performance during the WAVES_2007 campaign was a misaligned interference filter. With full laser power and a properly tuned interference filter, RASL is shown to be capable of measuring the main water vapor and aerosol parameters with temporal resolutions of between 2 and $45 \mathrm{~s}$ and spatial resolutions ranging from 30 to $330 \mathrm{~m}$ from a flight altitude of $8 \mathrm{~km}$ with precision of generally less than $10 \%$, providing performance that is competitive with some airborne Differential Absorption Lidar (DIAL) water vapor and High Spectral Resolution Lidar (HSRL) aerosol instruments. The use of diode-pumped laser technology would improve the performance of an airborne Raman lidar and permit additional instrumentation to be carried on board a small research aircraft. The combined airborne and ground-based measurements presented here demonstrate a level of versatility in Raman lidar that may be impossible to duplicate with any other single lidar technique.
\end{abstract}

Corresponding author address: David N. Whiteman, NASA/GSFC, Code 613.1, Bldg. 33, Rm. D404, Greenbelt, MD 20771. E-mail: david.n.whiteman@nasa.gov 


\section{Introduction}

Raman lidar technology has been deployed extensively for ground-based studies of aerosols (Ansmann et al. 1990; Ferrare et al. 2006), mesoscale meteorology (Melfi et al. 1989; Demoz et al. 2006), cirrus clouds (Ansmann et al. 1992; Reichardt et al. 2002; Whiteman et al. 2001a, 2004), and other topics. The use of Raman lidar from aircraft is much more limited, however. Heaps and Burris (1996) published upward-looking airborne methane measurements in the upper troposphere and lower stratosphere using Raman lidar in 1996. That system was designed to also make measurements of water vapor and temperature. Temperature measurements from this system were published in 1998 (Burris et al. 1998). This system was called the Airborne Raman lidar (ARL) and used two xenonfluorine $(\mathrm{XeF})$ excimer lasers and flew on either the C-130 or the DC-8 aircraft. More recently, an updated version of this system has been used extensively from a DC-8 aircraft to measure ozone, aerosols, and temperature (Burris et al. 2002). The limited use of Raman lidar technology for airborne profiling can be attributed to the facts that 1) its previous use was limited to nighttime, 2) the lidar systems deployed in aircraft have been quite large and thus incompatible with small research aircraft, and 3) differential absorption lidar systems compatible with smaller aircraft have successfully been used for water vapor profiling under a wide variety of daytime and nighttime conditions (Poberaj et al. 2002; Behrendt et al. 2007; Wulfmeyer et al. 2006).

Recent advances in the application of the Raman lidar technique (Whiteman et al. 2006a), however, have permitted capable daytime profiling of water vapor from ground-based platforms (Ferrare et al. 2006; Whiteman et al.2007). Also, numerical simulation (Whiteman et al. 2001b) indicates that a large performance advantage is achieved by operating a Raman water vapor lidar from an airborne platform looking downward versus that same system looking upward. Furthermore, if sufficient sensitivity is available for making water vapor mixing ratio measurements using the Raman lidar technique, then various other quantities, such as aerosol backscatter, extinction, depolarization, rotational Raman temperature (Di Girolamo et al. 2004), cloud liquid water (Whiteman and Melfi 1999), and carbon dioxide (Whiteman et al. 2007), are potentially measurable as well. Finally, a lidar operating in the UV portion of the spectrum, as the system to be described here, is considerably less hazardous to the eye than systems based on visible or IR lasers. Therefore, the expectations are that a broad range of atmospheric parameters can potentially be quantified simultaneously with an airborne Raman lidar that possesses shorter eyehazard distances than lidar systems operating in the visible or IR regions of the spectrum.
For these reasons, the National Aeronautics and Space Administration (NASA) funded the development of the Raman Airborne Spectroscopic Lidar (RASL) under the Instrument Incubator Program of the Earth Sciences Technology Office (ESTO). RASL was first operated in upward-looking mode from the laboratory in 2002 and later was used to demonstrate the highest signal-to-noise ratio (S/N) ground-based Raman lidar measurements of water vapor theretofore acquired (Whiteman et al. 2007). At the same time, RASL also demonstrated measurements of aerosol backscatter and extinction coefficients, aerosol depolarization, cloud liquid water, and carbon dioxide. Here, we present measurements from the first flights of RASL conducted during the summer of 2007 in Virginia, in support of the Water Vapor Validation Experiment-Satellite/Sondes (WAVES_2007) field campaign. These RASL flights on a Beechcraft King Air aircraft permitted the measurement capability for the water vapor mixing ratio, aerosol backscatter and extinction coefficient, and cloud liquid water to be demonstrated. As will be described, the RASL performance of all measurements except aerosol extinction and carbon dioxide met the expectations that were based on numerical simulation. This was the case despite persistently low laser power during the campaign.

Following this set of airborne measurements, the RASL hardware was installed in a mobile trailer in a configuration that is called Atmospheric Lidar for Validation, Interagency Collaboration and Education (ALVICE) and participated in the Measurements of Humidity and Validation Experiment (MOHAVE-II) at Table Mountain, California, during October 2007. The results of that campaign are detailed in the ground-based section of this paper. The data acquired during MOHAVE-II permitted a numerical simulation study to be performed to help determine the cause of the anomalously poor aerosol extinction performance demonstrated by RASL during the WAVES flights.

The paper is structured as follows. The RASL instrument hardware is described, placing most emphasis on the subsystems that were developed to accommodate RASL in a small research aircraft. Following this, demonstration measurements of the water vapor mixing ratio, aerosol backscatter and extinction coefficient, and cloud liquid water are presented and comparisons are made with ground-based instruments when available. Projections of RASL performance are then presented, assuming full laser power and optimized filter settings. Simple comparisons are then made between this projected performance and that of other existing airborne lidar systems. Following this, the ground-based deployment of the ALVICE instrument to the Table Mountain Facility is described. The initial measurements made during MOHAVE indicated that 
ALVICE measurements were extending usefully into the lower stratosphere. Numerical simulation is used to demonstrate that a system with the configuration of ALVICE should be expected to deliver such performance extending to the very low water vapor concentrations in the lower stratosphere. Numerical simulation is also used to help identify the source of the low performance of RASL during the WAVES_2007 field campaign. Techniques for improving upper-tropospheric-lower-stratospheric (UT-LS) measurements of water vapor using Raman lidar are discussed.

\section{Airborne measurements during the WAVES_2007 field campaign}

The first of the two field campaigns that are described here was the WAVES_2007 campaign hosted at the Howard University Research Campus in Beltsville, Maryland. RASL made its first flights during this campaign.

\section{a. The Raman Airborne Spectroscopic Lidar flight subsystems}

The Raman Airborne Spectroscopic Lidar was developed under the NASA Instrument Incubator Program (IIP) and was first tested from the ground during September 2002 (Whiteman et al. 2007). Under further support of the IIP program in 2006 and 2007, RASL was adapted for flight on a Beechcraft King Air B200 and was first flown during July and August 2007. RASL consists of a Continuum $9050 \mathrm{Nd}$ :YAG laser emitting at the frequency-tripled wavelength of $354.7 \mathrm{~nm}$ with a nominal output power of 17.5 W, a 0.6-m Dall-Kirkham telescope manufactured by DFM Engineering, dichroic beam splitters and interference filters from Barr Associates that select a set of spectral measurements, Hamamatsu R1924 photomultiplier tubes that detect the signal, and Licel analog-to-digital and photon-counting data acquisition. The specifications of the base lidar system have been detailed recently (Whiteman et al. 2007), so the main subsystems developed to permit flight in a small research aircraft will be detailed here. Those subsystems are an automated bore-site alignment system, laser power optimization feedback system, matrix window assembly, and a radiative cooler.

\section{1) Bore Site ALignMENT SYSTEM}

To maintain the optimum $\mathrm{S} / \mathrm{N}$ of the lidar measurements and to maximize the stability of the measurements, it is highly desirable that the relative alignment between the outgoing laser beam and the telescope field of view be tightly constrained. Operations in a laboratory setting generally include the mounting of both the laser and telescope on a rigid optical table, minimizing the relative motion that might occur over a short period of time. However, the thermal and vibrational environment offered by a small research aircraft such as the King Air implied that operation of a $0.6-\mathrm{m}$ telescope at a narrow field of view of $0.25 \mathrm{mrad}$ was best done with a feedback system to ensure optimal alignment of the outgoing laser beam and the telescope field of view under a range of flight conditions. We refer to such a system as a "bore site" alignment system.

The image formed by a telescope observing a laser beam propagating close to the optical axis in the far field is a spot near the telescope image plane. The size of the spot is related to the divergence of the laser beam. The $x-y$ position of the spot is related to where within the laser field of view the laser beam, assumed to possess a divergence smaller than the telescope field of view, is located. So, the principle involved in developing the bore-site system is to, by using lenses, optically relay an image of the field stop onto a position-sensitive detector and monitor the motion of the spot due to the imaged laser beam. Optimum alignment would place the laser spot at the center of the field of view. A system that performs a similar function has flown previously (Hair et al. 2008).

The hardware used in the bore-site system involves a set of four photo sensors, photon-counting electronics for each sensor, and a fiber optic bundle to gather the signal from the relayed field stop to the photo sensors. The photo sensors and photon-counting electronics were taken from a commercially available system manufactured by Licel (Berlin, Germany) that is based on a concept developed at NASA's Goddard Space Flight Center (GSFC). This system uses a Hamamatsu H7546B 64-channel photomultiplier tube (PMT), where just the central four channels are active in our application. The fiber optic, made by Fiberguide Industries, consisted of a bundle of $100-\mu \mathrm{m}$ core fused-silica fibers separated into four sets and performs a similar function as the fiber described by Hair et al. (2008). The end of the fiber placed at the relayed telescope focal plane had the bundles arranged in a circular shape, thus forming a secondary field stop, while the end of the fiber that mated to the PMT had the bundles arranged in four square cells with spacing set to match that of the central four channels of the PMT. The reasons for coupling the relayed field stop to the PMT via a fiber bundle instead of placing the PMT itself at the relayed field stop position were 1) to reduce the "edge effects" of the laser spot moving over dead zones of the PMT and 2) to simplify the mechanics of mounting the bore-site PMT since only the low-mass fiber optic had to be mounted at the relayed field stop position instead of the entire PMT with its electronics. We were not able to simulate in advance how rapidly laser realignments would be required from an airborne platform; therefore, 
the system was designed with sufficient signal to noise to permit useful changes in the pointing of the outgoing laser within a period of 1-2 s. The instrument proved to be sufficiently stable that 5-10 s or more of accumulation time could be used to determine the position of the laser spot. This extended accumulation time decreased the random noise in the spot location assessment and permitted the laser alignment to be held generally within $\pm 25 \mu \mathrm{rad}$.

\section{2) LASER POWER FEEDBACK SYSTEM}

The laser used in RASL is a Continuum 9050 operating with adjustable harmonic crystals for generating the second and third harmonic outputs. The housings for the crystals are temperature controlled, but experience has shown that even in laboratory settings, these crystals require periodic adjustments to maintain optimum power. In the confines of a small research aircraft, the instrument is subjected to mechanical vibrations and thermal variations. Because of this, we anticipated that more frequent adjustments might be necessary to maintain optimum power when compared with a laboratory setting. For this reason a system of monitoring and adjusting the harmonic crystals was developed. Silicon photodiodes were mounted inside the laser head to monitor the laser output power at the three output wavelengths. Interference filters were fitted on each of the photodiodes to choose one of the three wavelengths of interest. Custom circuitry was developed to condition and capture the photodiode signals. A C language computer program interfaced to a LabView Graphic User Interface (GUI) performed the optimization by adjusting the harmonic crystals while observing the signal intensities from the photodiodes. In general, the feedback system was able to maintain the power within $10 \%-20 \%$ of the peak value.

\section{3) MATRIX Window ASSEMBLY}

RASL uses a 0.6-m aperture telescope and operates in the UV portion of the spectrum. The traditional approach of accommodating such a system in an aircraft would be to use a port window made of fused silica with an aperture slightly larger than $0.6 \mathrm{~m}$. To maintain an internal cabin pressure of approximately $2.4 \mathrm{~km}$ pressure altitude, the port window must maintain integrity under flight conditions that present a significant pressure differential between the inside and outside of the aircraft. As the aperture of the window increases, therefore, so must its thickness in order to withstand this differential. A 0.6- $\mathrm{m}$ aperture fused-silica window for use in aircraft that fly to altitudes of $10 \mathrm{~km}$ or greater would need to be up to $5 \mathrm{~cm}$ thick. The costs of such a window with an ARcoated central region for transmission of the RASL laser were obtained from vendors and found, in the early 2000 s, to approach $\$ 100,000$. To save money, another

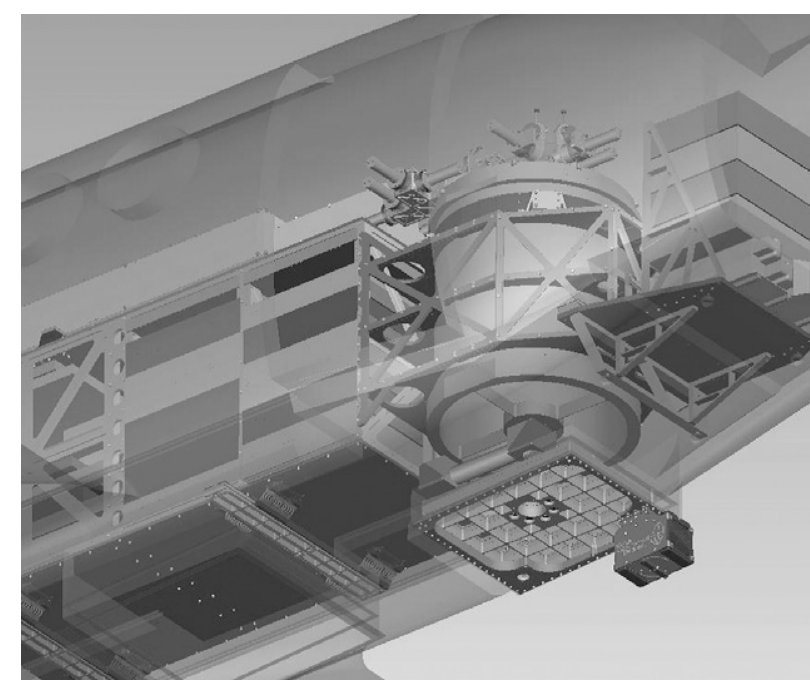

FIG. 1. An engineering drawing of the matrix window used for the RASL first flight. The instrument is installed in the belly of the B200 aircraft. Note the asymmetrical layout of the matrix window due to the limited port area in the B200. The double radiators that are part of the cooling system are mounted to the window.

solution was engineered for the RASL system based on the concept of a matrix window, as shown in Fig. 1. This engineering drawing shows the window installed beneath the telescope in the belly of the King Air B200. The radiative cooler that is described in the next subsection hangs from the window.

The matrix window frame consists of pocketed cells machined out of a single piece of flight-grade aluminum. The frame accommodates $2410-\mathrm{cm}^{2} \times 1.9-\mathrm{cm}$-thick fused silica windows arranged, as shown in Fig. 1. To ensure that the individual windows did not produce differential steering of the beam, the parallelism of the individual windows was 5 arc seconds or better. Note that the use of a large number of smaller windows greatly decreases the thickness of the glass required to maintain the pressure differential of the aircraft. We estimate that the cost savings of implementing the RASL window using this matrix approach versus the use of a single piece of fused silica was more than $\$ 75,000$.

The available port on the B200 was not large enough to permit the use of the full $0.6-\mathrm{m}$ aperture of the RASL telescope; therefore, the matrix window was built with the central laser transmit window off-center, as shown in Fig. 1. Approximately $75 \%$ of the telescope aperture was available with this configuration. The one drawback to the use of a matrix configuration for the window was a significantly increased tendency for the window to develop a coating of frost during flight at high altitudes where the outside temperature could reach $-50^{\circ} \mathrm{C}$ or colder. To maintain a frostfree window during flight, $15-\mathrm{cm}$-diameter ducts were used 


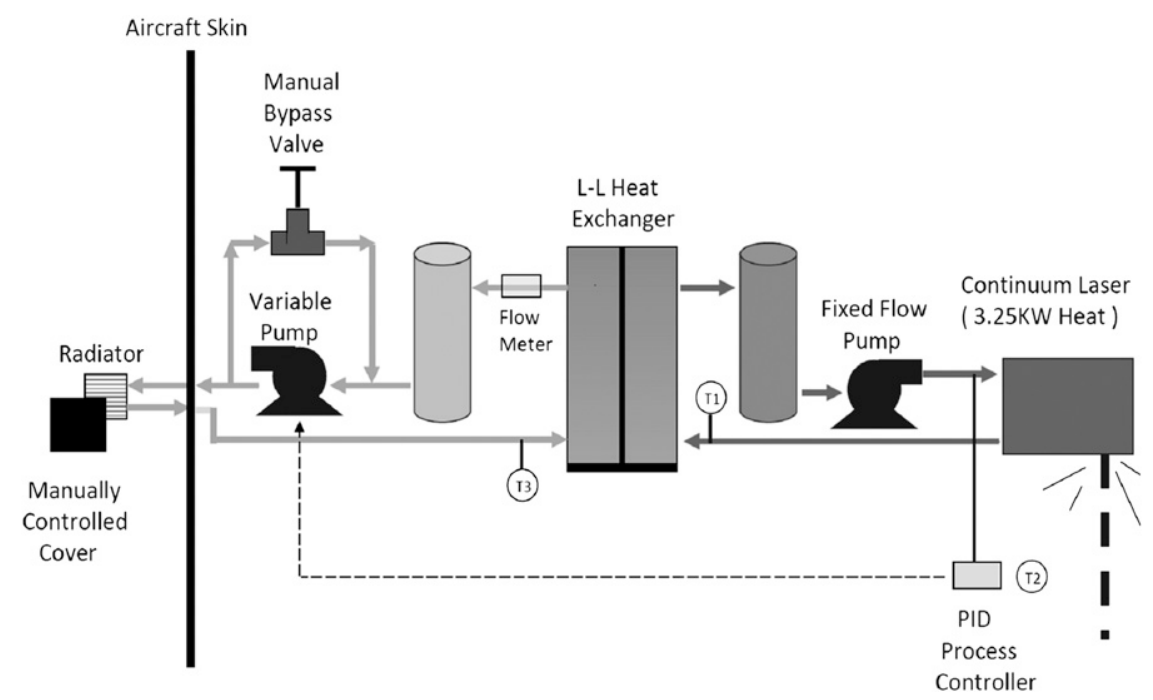

FIG. 2. Diagram of the radiative cooling system used in the RASL flight configuration. The external loop uses a variable speed pump to warm fluid through the external radiators. The cooled return flow exchanges heat with the internal loop that delivers cooled water at constant flow to the laser. Fluid reservoirs, shown as cylinders in the diagram, serve as buffers in the system and also help to remove bubbles.

to route waste heat from the laser electronics bay onto the matrix window. In addition, pipe heater cables, such as are used to prevent freezing in water pipes, were wrapped around the outer perimeter of the window frame.

\section{4) RADiATIVE COOLER}

A flash-lamp-pumped laser like the Continuum 9050 generates approximately $3.5 \mathrm{~kW}$ of waste heat. Normal laboratory use of such a laser system would include a chilled water source for removing the excess heat generated by the laser. There was neither weight nor power capacity for flying a closed loop water chiller in the King Air B200 along with the other RASL instrumentation. Therefore, we designed and implemented a radiative cooling system for this purpose. As flown, it was able to dissipate the full laser heat provided that the external temperature and wind speeds were adequate. A layout of the radiative cooling system is shown in Fig. 2. The cooling system consisted of two separate water loops that exchanged heat through a closed heat exchanger. The fluid in the external loop was pumped by a variable speed pump designed for medical use where the rate of flow was determined by a proportional-integral-derivative (PID) controller that received input from thermistors (T1, T2, and $\mathrm{T} 3$ in Fig. 2) placed at different locations in the system. This external loop exchanged heat to an internal water loop that flowed at constant speed and constant temperature to the laser itself. This internal loop, therefore, mimicked the operation of a laboratory chiller. Two radiators were used in series and were mounted to the matrix window assembly. The radiators used were originally designed for use in cooling computer CPU chips and the window frame was designed such that the channels through which the liquids flowed to and from the radiators were bored into the window frame itself. The system was able to dissipate the waste heat of the laser and supply the desired $20^{\circ} \mathrm{C}$ water to the laser provided a cruise speed of approximately $100 \mathrm{~m} \mathrm{~s}^{-1}$ was maintained at an altitude of $7 \mathrm{~km}$ or greater. Below this altitude, the water supplied to the laser would reach an equilibrium point at a temperature higher than $20^{\circ} \mathrm{C}$.

\section{b. Previous simulations of airborne Raman lidar measurements of water vapor mixing ratio}

During the early phases of the development of the RASL instrument, numerical simulations were performed to predict the measurement capability of an airborne Raman lidar with the anticipated configuration of RASL (Whiteman et al. 2001b). These will now be reviewed as a reference for the actual measurements shown in upcoming sections. The efficiency factors used in those simulations were determined from ground-based measurements by Raman lidar systems operated by NASA GSFC and the Department of Energy. The simulations indicated that a Raman lidar system operated from an airborne platform benefits by a large decrease in dynamic range for the measurement of Raman scattering from both water vapor and nitrogen when compared with measurements by the same hardware operated from the 
ground. This decrease in dynamic range results in a large decrease in averaging time and is a general characteristic of downward-looking lidar systems. The modeling simulations also show that in general the solar background is lower for an airborne Raman lidar looking downward than for a ground-based one looking upward. The simulations indicated that profiles from a $10-\mathrm{km}$ flight altitude with approximately $10 \%$ random uncertainty could be achieved with 3 minutes of averaging time during the daytime and as little as $10 \mathrm{~s}$ at night. Assuming $100 \mathrm{~m} \mathrm{~s}^{-1}$ aircraft speed, as in the aircraft used in the flights discussed here, these averaging times correspond to 18 and $1 \mathrm{~km}$, respectively. The simulations also indicated that the dynamic range compression would permit such measurements to be achieved using a single detector per measurement wavelength instead of the more typical two detectors used in groundbased upward-looking Raman lidar systems. As we will show, if the airborne lidar system has sufficient sensitivity to measure the water vapor mixing ratio, then other measurements such as aerosol backscatter and extinction and cloud liquid properties are also possible.

\section{c. Flight measurements}

RASL was first flown during the WAVES_2007 field campaign, which was hosted at the Howard University Research Campus in Beltsville, Maryland, in JuneAugust 2007 under the auspices of the NASA Aura Validation program. RASL was based at Dynamic Aviation in Bridgewater, Virginia. A general problem that existed during this first deployment of RASL was related to the fact that at the time of the RASL mission various other aircraft owned by Dynamic Aviation were being prepared for classified, high-priority missions funded by the Department of Defense. The preparation of these other missions fully utilized the available hangar space and environmental control systems. Therefore, after RASL was fully integrated, the aircraft was stored outside the hangar without any external environmental controls. This subjected the aircraft and the RASL instrumentation to wide extremes of temperature under nonoperational conditions. We believe that these extremes of thermal conditions are what led to the persistent, suboptimal performance of the RASL laser, which is designed for more controlled laboratory use. The lidar measurements presented here were therefore acquired with a laser output power of 3-6 W at $355 \mathrm{~nm}$ instead of the nominal 17.5 W for the Continuum 9050. We will later provide performance projections assuming full laser power. In the following subsections, examples of the various measurements made by RASL during its first flight campaign will be presented. For reference, there were nine RASL flights from 1 July to 2 August 2007, although several of these flights were engineering in nature and did not produce useful science data. Because of budget constraints, fully quality controlled data products could not be created; therefore, only quick-look results will be presented here.

\section{1) WATER VAPOR MIXING RATIO}

Raman water vapor lidar systems operating outside of the solar-blind region have significantly different performance during the daytime and the nighttime because of the relatively weak Raman signals and the relatively strong solar background (Whiteman et al. 2007). Here, we show examples of daytime and nighttime profiles from the RASL system during the flight campaign.

\section{(i) Daytime}

The first flight of RASL occurred on 1 July 2007. The aircraft exhibited severe pressurization issues and the RASL laser could not be started so this initial flight was aborted. Maintenance was performed on the aircraft pressurization system and a loose plug was attached to the three-phase inverters required for laser operations. The first data flight of RASL therefore occurred on 2 July 2007 between approximately 2200 and 0000 UT on 3 July, when the solar zenith angle varied from approximately $28^{\circ}$ to $8^{\circ}$ above the horizon and the aerosol optical thickness at $355 \mathrm{~nm}$ was approximately 0.7. Problems with the aircraft pressurization system persisted during this flight and thus limited the maximum altitude of the flight to approximately $7 \mathrm{~km}$. In addition, the bore-site alignment system was not functioning nominally during this flight, necessitating a manual alignment of the laser to the telescope field of view. The alignment was performed by varying the RASL field of view from larger values to smaller values and progressively reoptimizing the signal. During this procedure, the final fov setting was inadvertently left at $350 \mu \mathrm{rad}$ instead of the desired 250 $\mu \mathrm{rad}$. This operational error increased the solar background present in the profiles by approximately a factor of 2 , thus increasing the background noise and degrading the measurement performance. The intended flight plan was to climb to $8.6 \mathrm{~km}$ MSL and overfly the Washington, D.C., metropolitan area and the Howard University Beltsville Campus (HUBC), where a radiosonde launch was to occur simultaneously with the overflight. The aircraft pressurization problems prevented the plane from reaching a sufficient altitude to permit this flight to occur, however. Instead, an improvised flight in the vicinity of Bridgewater was performed, but the recording of the GPS data did not function properly on this first flight, preventing exact knowledge of the flight track for postanalysis.

Figure 3 shows the water vapor mixing ratio, water vapor random error, and vertical smoothing window size. The RASL water vapor mixing ratio profile acquired at 23.75 UTC during this flight using a preflight calibration 

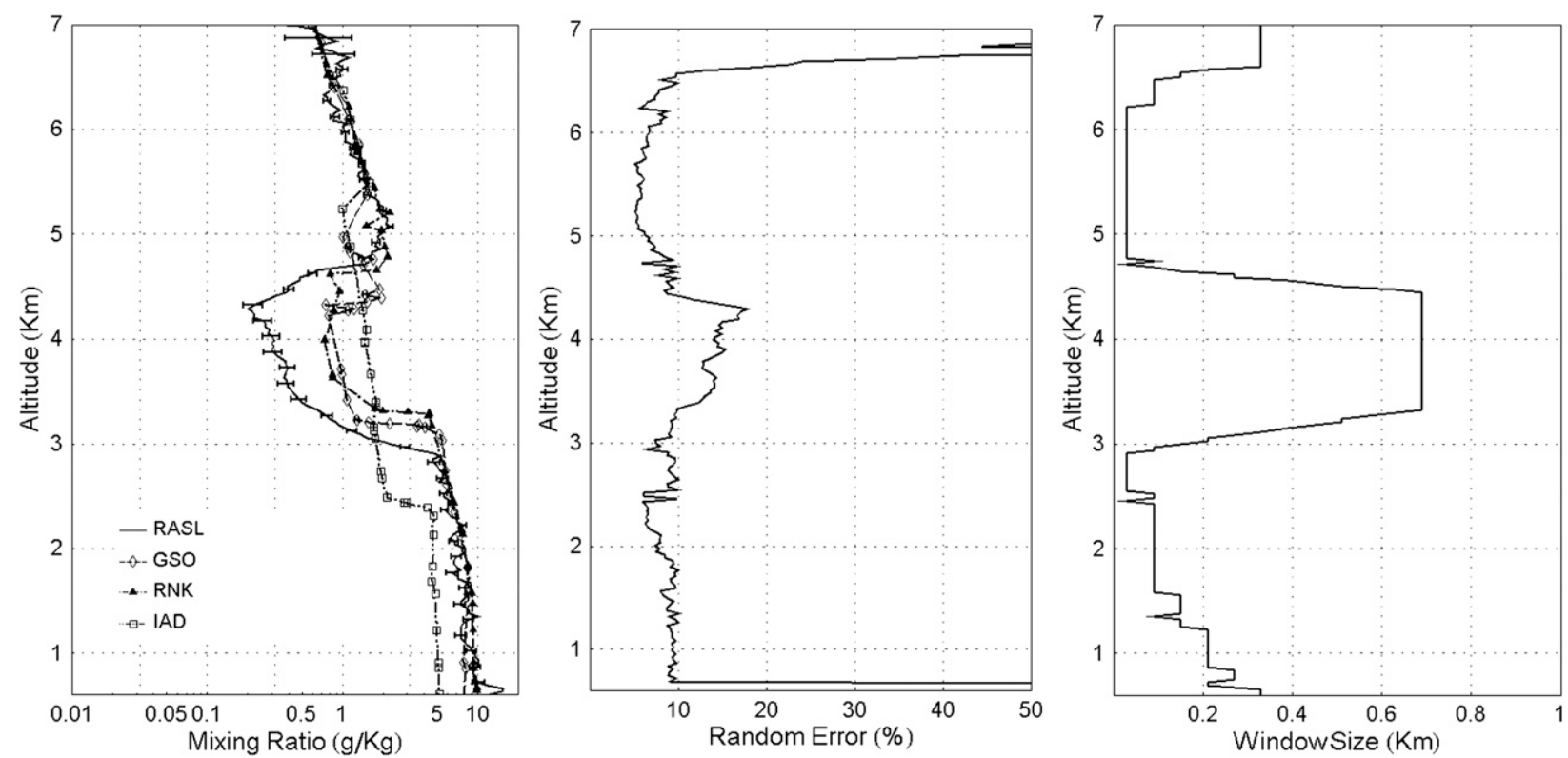

FIG. 3. (left) RASL water vapor mixing ratio measured during the daytime on 2 July 2007 plotted vs three National Weather Service radiosondes launched in the general area of the RASL flight. The RASL averaging time is $50 \mathrm{~s}$. (middle) The RASL random errors. (right) The smoothing window size used in the analysis. The following figures use a similar layout.

constant obtained during ground-based testing of RASL is shown in Fig. 3 (left) (Whiteman et al. 2007). Also shown in Fig. 3 for reference are three standard National Weather Service radiosonde launches at 0000 UTC 3 July from the Greensboro, North Carolina; Blacksburg, Virginia; and Washington Dulles International Airport sounding sites. An averaging time of $50 \mathrm{~s}$ was used for this profile. This corresponds to a horizontal resolution of about $5 \mathrm{~km}$ given an aircraft flight speed of approximately $100 \mathrm{~m} \mathrm{~s}^{-1}$. The vertical resolution was determined by an adaptive, moving-window, smoothing routine that, except in the dry region centered at $4 \mathrm{~km}$, varied the window size between 30 and $300 \mathrm{~m}$ with the goal of maintaining $10 \%$ or less random error. In the dry portion of the profile, the vertical window was permitted to increase to as large as $700 \mathrm{~m}$ to reduce the random uncertainty. The resulting random errors remain below $10 \%$, except for the dry region of the profile where the minimum mixing ratio encountered was approximately $0.2 \mathrm{~g} \mathrm{~kg}^{-1}$.

\section{(ii) Nighttime}

On the night of 3 August 2007 the conditions were present for a nocturnal low-level jet (LLJ) (Zhang et al. 2006) to establish itself over the mid-Atlantic region. The aircraft pressurization problems had been resolved; therefore, a RASL mission was flown at $8.6 \mathrm{~km}$ over the Washington-Baltimore, Maryland area following an hour-glass-shaped flight pattern in order to measure different portions of the anticipated LLJ. This flight altitude was sufficiently high that, even in the complex airspace of the Washington metropolitan area, the intended pattern could be performed without interference from flight controllers. The center of the hourglass pattern was located over the HUBC site where four overpasses occurred during the mission. Radiosondes and Raman lidar measurements were made from HUBC during the RASL flight. In addition, two overpasses were made of the University of Maryland, Baltimore County (UMBC), campus, where additional lidar measurements occurred. Figure 4 shows a comparison of water vapor mixing ratio measurements made by RASL, the Howard University Raman lidar (HURL), and a Väisälä RS92 radiosonde. The HURL Raman lidar (Adam et al. 2007, 2010) uses a 16 -in. telescope operating at a $0.25-\mathrm{mrad}$ field of view and a Continuum 9030 laser that was generating approximately $8 \mathrm{~W}$ at $355 \mathrm{~nm}$ during these measurements. The time of the two lidar measurements is 0656 UTC. The radiosonde launch time was 0640 UTC. An averaging time of $10 \mathrm{~s}$ (horizontal resolution of approximately $1 \mathrm{~km}$ ) was used for the RASL data while an averaging time of $60 \mathrm{~s}$ was used for the HURL data. Generally good agreement was obtained among all measurement systems although a tendency toward a moist bias was observed in the upper portions of the HURL profile that is still under investigation. The RASL and RS92 profiles agree well in their overall representations of moisture features as well as in their calibration. 

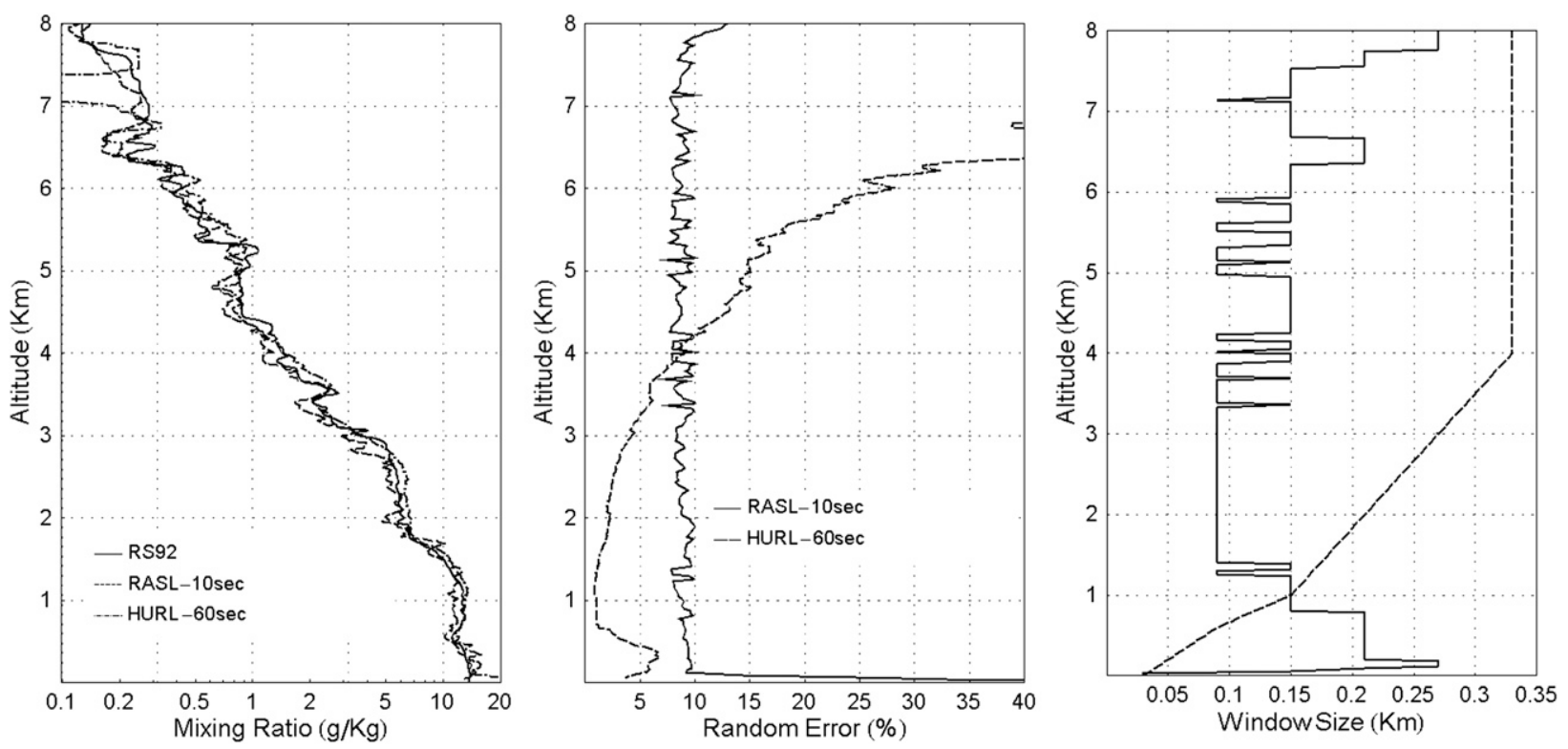

FIG. 4. As in Fig. 3, but for RASL water vapor mixing ratio on the night of 3 Aug 2007 using 10 s of averaging. Also shown are mixing ratio profiles from the Howard University Raman lidar and a Vaisala RS-92 radiosonde launched from the Beltsville site near the time of the RASL overpass.

The comparison of RASL and HURL random errors shown in the middle panel of Fig. 4 illustrates well the differences in the random error characteristics of an airborne Raman lidar versus a ground-based one. Through the use of the adaptive smoothing routine, the RASL random errors remain at or below $10 \%$ throughout most of the profile. The variable sizes of the smoothing windows used to process the RASL and HURL data are shown as a function of altitude on the right-hand side of Fig. 4. The RASL and HURL smoothing windows were permitted to expand to as large as 270 and $330 \mathrm{~m}$, respectively, in the data processing. The RASL vertical resolution generally remains between 100 and $200 \mathrm{~m}$ except in the portions of the profile just below the aircraft and just above the ground where the window size expanded to the maximum permitted $270 \mathrm{~m}$ in an attempt to maintain errors below the $10 \%$ goal. Errors increase just below the aircraft due to the signal compression (Harms et al. 1978) associated with the narrow field of view $(0.25 \mathrm{mrad})$ used in the RASL telescope. To compensate for this, the vertical smoothing window increases for ranges closer to the aircraft than approximately $1 \mathrm{~km}$. Random uncertainty in the RASL profile also increases near the ground faster than dictated by the range-squared law due to the increase in extinction that occurs in the boundary layer. The HURL error profile displays the general increase in random error with altitude that is characteristic of a ground-based Raman water vapor lidar system. In the case of HURL, the random error is generally less than $5 \%$ below $3 \mathrm{~km}$ and increases to more than $30 \%$ above $6 \mathrm{~km}$. The increase in random error in the HURL profile below $1 \mathrm{~km}$ is due to the same near-field signal compression observed below the aircraft in the RASL profile.

\section{2) Aerosol depolarization}

Example volume depolarization measurements from the daytime RASL flight on 2 July 2007 are shown in Fig. 5. The averaging time for these measurements was $3 \mathrm{~s}$ (approximately $300-\mathrm{m}$ horizontal resolution). The vertical window size was varied between 30 and $90 \mathrm{~m}$, yielding a random error of between $2 \%$ and $5 \%$ throughout the profile. Only an approximate calibration has been performed on this profile using the assumptions that clear air existed at an altitude of $6.5 \mathrm{~km}$ and that the molecular depolarization consistent with the RASL 355-nm interference filter was $1.0 \%$ (Behrendt and Nakamura 2002). Small enhancements are observed in the depolarization profile above 3 and $4 \mathrm{~km}$, respectively. Data below $1 \mathrm{~km}$ AGL are not shown due to interference with the ground.

\section{3) Aerosol backscatter}

Figure 6 presents the aerosol backscatter coefficient measurements from 2 July 2007 using a temporal average of $5 \mathrm{~s}$ and variable vertical smoothing that ranged adaptively between 30 and $270 \mathrm{~m}$. The atmospheric boundary layer can be observed to extend up to an altitude of approximately $3 \mathrm{~km}$. The $10 \%$ target random error was 

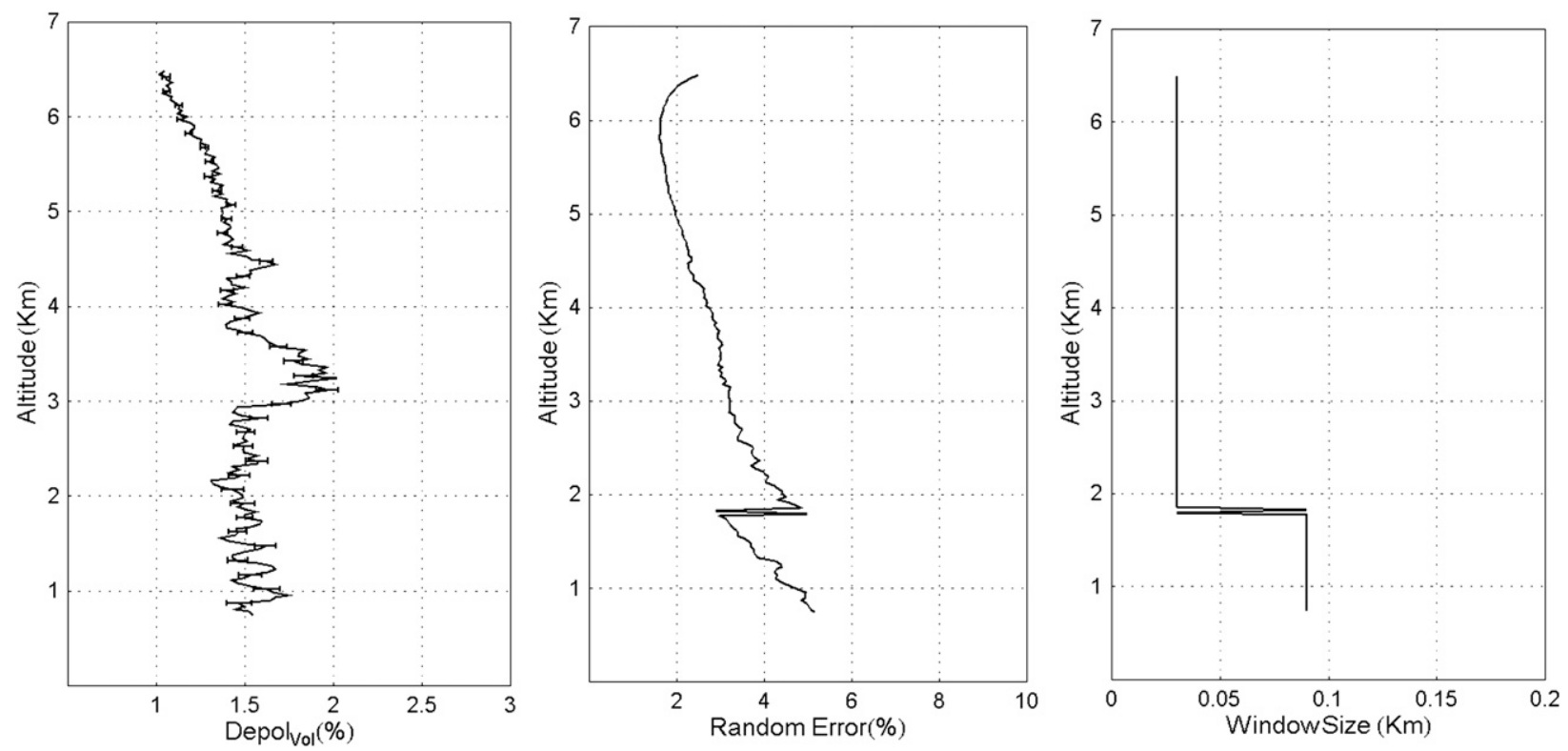

FIG. 5. As in Fig. 3, but for aerosol depolarization measured by RASL on 2 Jul 2007. Averaging time is 3 s. The random error and vertical smoothing windows are also shown.

achieved for most of the profile using $100 \mathrm{~m}$ or smaller window size. Near the ground the window size increased to $150 \mathrm{~m}$ to maintain the $10 \%$ random error. In the region of the atmosphere at approximately $6.5 \mathrm{~km}$ where very low aerosol concentrations were present, the adaptive routine was unable to achieve $10 \%$ random error using a window size of $270 \mathrm{~m}$.

\section{4) Aerosol extinction And EXTINCTION-TO-BACKSCATTER RATIO}

All the measurements described above met or exceeded performance expectations despite the low laser power achieved. The aerosol extinction measurements demonstrated by RASL during this first flight deployment,
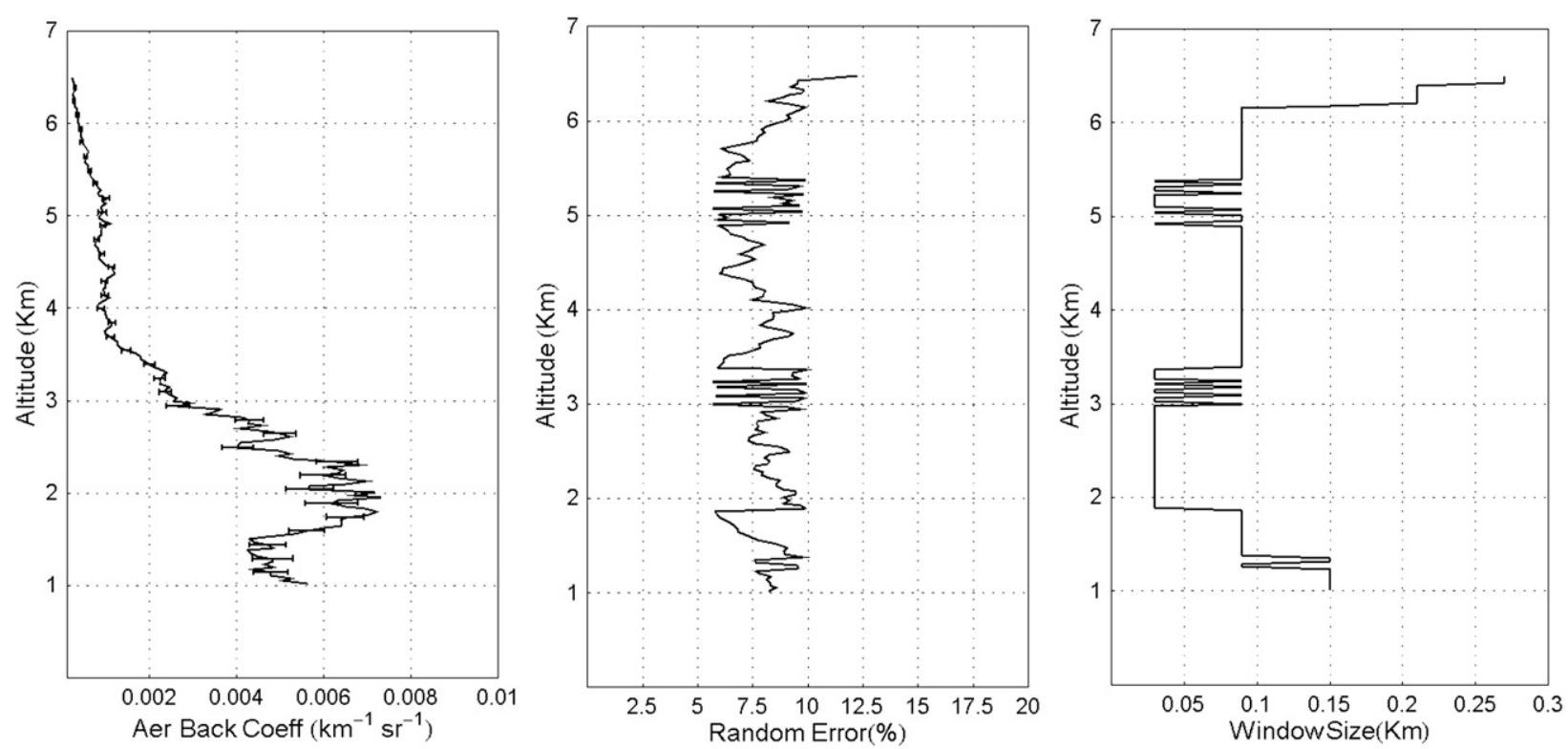

FIG. 6. As in Fig. 3, but for RASL aerosol backscatter coefficient measured with $5 \mathrm{~s}$ of averaging time during the daytime on 2 Jul 2007 . The random errors and vertical smoothing windows are also shown. 

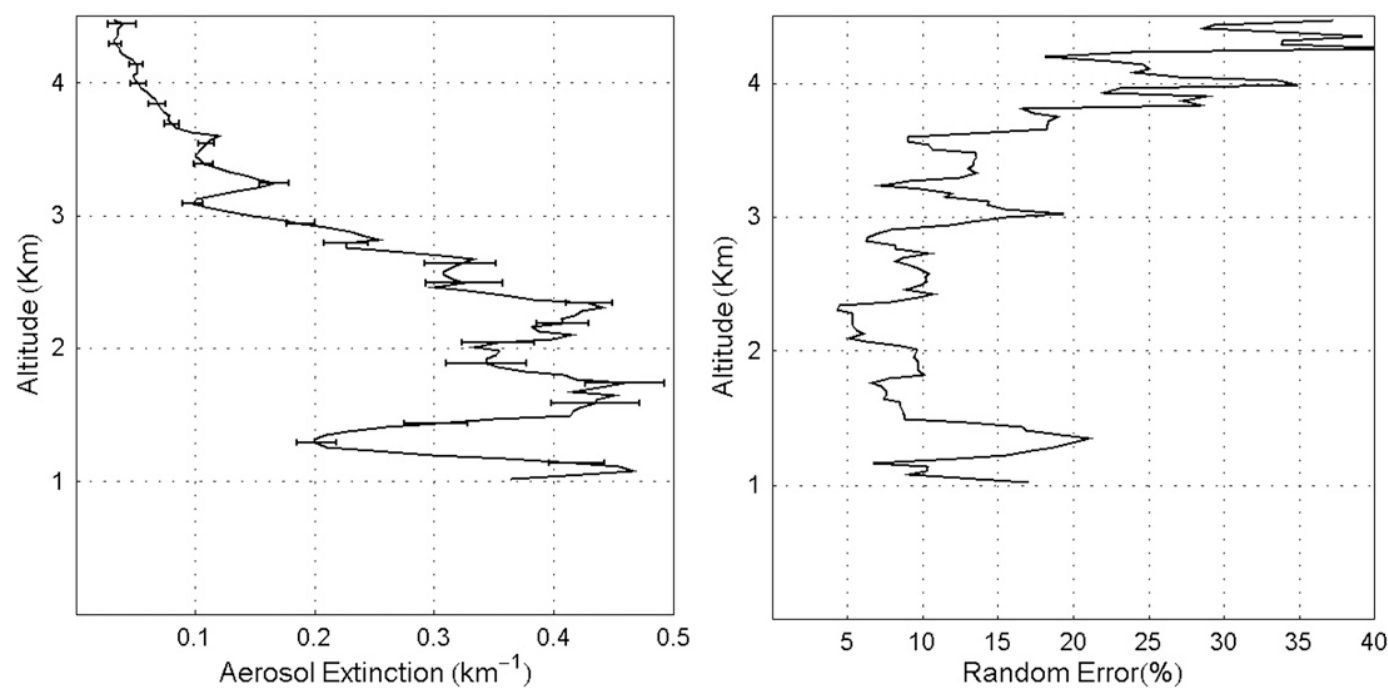

FIG. 7. (left) Daytime aerosol extinction $(210 \mathrm{~s}, 330 \mathrm{~m})$ on $2 \mathrm{Jul}$ 2007. (right) The random errors in the retrieval.

however, did not. Previous simulations indicated that, under the conditions present on 2 July 2007, aerosol extinction measurements with approximately $10 \%-20 \%$ random error should have been possible with temporal and spatial averaging thresholds of approximately $20 \mathrm{~s}$ and $300 \mathrm{~m}$, respectively. An example profile of the aerosol extinction acquired by RASL on 2 July 2007 is shown in Fig. 7. The temporal and spatial smoothing thresholds used in this figure are $210 \mathrm{~s}$ and $330 \mathrm{~m}$, respectively. The resulting random errors are generally below $20 \%$ except for extinction values below approximately $0.05 \mathrm{~km}^{-1}$ that occur toward the top of the profile. The corresponding ratio of extinction and backscatter (lidar ratio) using the same smoothing parameters is shown in Fig. 8. The random error curves for extinction and lidar ratio are essentially the same because the contribution to the lidar ratio error budget by the uncertainty in the backscatter coefficient, when smoothed to the same resolution as the extinction profile, is negligible. The implication from these considerations is that the RASL aerosol extinction temporal resolution during the flight campaign was approximately an order of magnitude poorer than anticipated. The numerical simulation studies presented in section 4 indicate that a misalignment of the $0.1 \mathrm{~nm}$ interference filter used in the RASL $\mathrm{N}_{2}$ channel was the likely cause of this suboptimal aerosol extinction performance. In section $2 \mathrm{~d}$ performance projections based on an optimized RASL system will be presented.
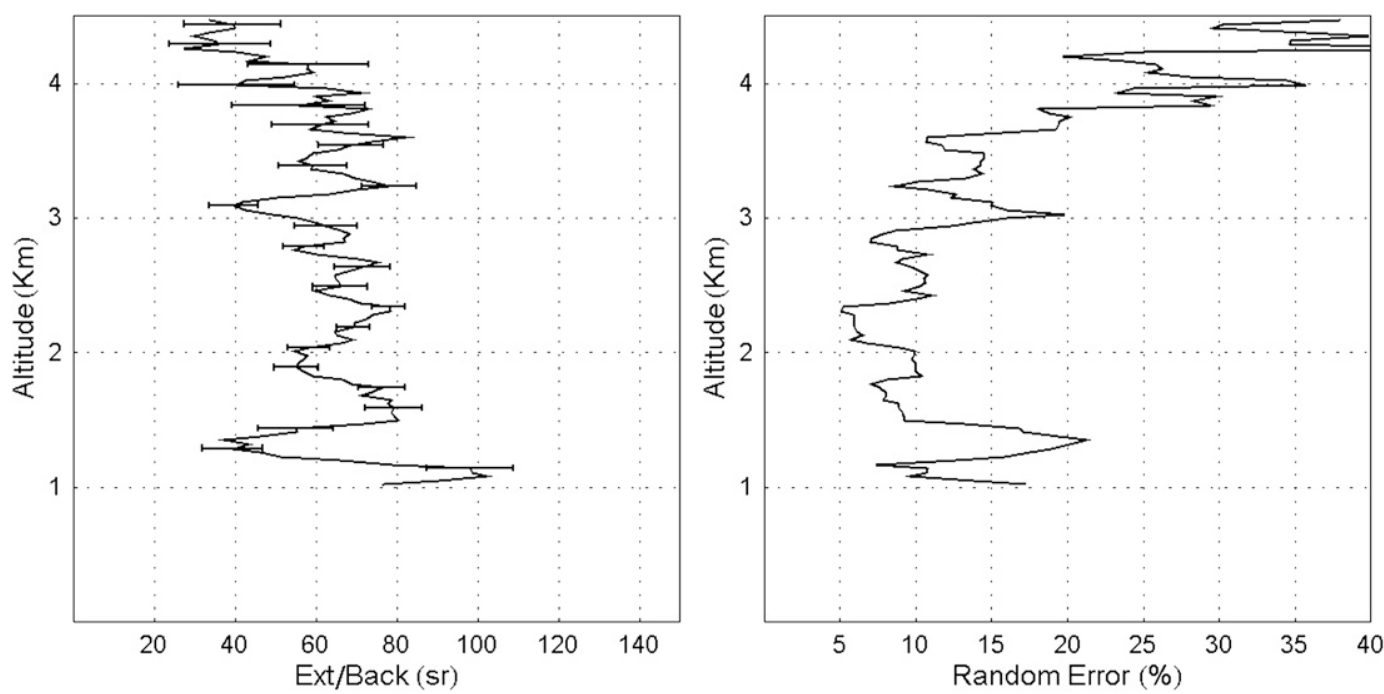

FIG. 8. As in Fig. 7, but for extinction to backscatter ratio (lidar ratio) measured during the daytime on 2 Jul 2007. 


\section{5) LIQUID WATER MEASUREMENTS}

Remote measurements of Raman scattering from liquid water were reported by Inaba and Kobayashi (1972) and in earlier publications therein. The first rangeresolved measurements of Raman scattering from suspended liquid in the atmosphere, in the form of fog, were reported by Bukin et al. (1983). Since that time, Melfi et al. (1997) have discussed the use of Raman scattering from cloud droplets to quantify the liquid water content of clouds. Whiteman and Melfi (1999) demonstrated a retrieval technique for both the cloud liquid water content and droplet radius although the data available at that time had the liquid and vapor signals present in the same optical channel. Veselovskii et al. (2000) measured the signals from liquid and vapor separately, but not simultaneously, by use of different interference filters inserted into the same optical channel. Rizi et al. (2004) demonstrated separate and simultaneous liquid and vapor measurements and retrievals from those data. Separated liquid and vapor measurements have also been implemented on the Department of Energy's Raman lidar system in Oklahoma. Russo (2007) used these data to retrieve the cloud liquid water content and droplet radius. These retrievals were used along with aerosol extinction measurements to study the aerosol indirect effects using Raman lidar. A similar scheme of measuring Raman scattering from both liquid and vapor simultaneously was previously available on the Scanning Raman Lidar (SRL; Whiteman et al. 2006a) and has been implemented in RASL as well. Note that for all of these implementations, the measurements have been limited to nighttime due to the fact that the Raman signal from liquid water is generally weaker than that from water vapor and covers a spectrum more than an order of magnitude wider $(\approx 5$ versus $0.3 \mathrm{~nm}$ ). The liquid water signals are generally weaker despite a cross section approximately 5 times higher (Weber 1979; Slusher and Derr 1975) than water vapor because of the typically lower number density of liquid versus vapor in a cloud. The channel characteristics are shown in Table 1 . The retrieval techniques used here for the RASL data are the same as in Russo (2007). It should be noted that the same channel that is used for liquid water returns can also provide useful information on the ice content of cirrus clouds (Wang et al. 2004).

The nighttime RASL flight on 3 July 2007 presented the opportunity to test the liquid water measurement capability of the system. A continuous layer of geometrically thin clouds that varied in altitude from 2.5 to $3.0 \mathrm{~km} \mathrm{MSL}$ was overflown. This portion of the flight was made in the vicinity of the foothills of the Appalachian Mountains where an upslope wind aided the development of the cumulus clouds sampled. Profiles of liquid water content
TABLE 1. Specifications of the RASL instrument as flown during the WAVES_2007 campaign.

\begin{tabular}{|c|c|}
\hline Laser & $\begin{array}{l}\text { Nd:YAG }(355 \mathrm{~nm}), 350 \mathrm{~mJ} \text { pulse }{ }^{-1}, 50 \mathrm{~Hz} \\
\text { (Continuum } 9050), \times 5 \text { beam expander, } \\
\text { 0.1-mrad output divergence }\end{array}$ \\
\hline Telescope & $\begin{array}{l}\text { Custom, athermal, } 0.6 \mathrm{~m} \\
\text { (DFM Engineering) }\end{array}$ \\
\hline Data acquisition & $\begin{array}{l}\text { 250-MHz photon counting and } 20-\mathrm{MHz} \\
\text { analog detection (Licel) }\end{array}$ \\
\hline Range resolution & $7.5 \mathrm{~m}$ \\
\hline \multirow{4}{*}{\multicolumn{2}{|c|}{$\begin{array}{l}\text { Measurements } \\
\text { Wavelength (nm) } \\
\text { Bandpass (nm) } \\
\text { Transmission (\%) }\end{array}$}} \\
\hline & \\
\hline & \\
\hline & \\
\hline & Water vapor/407.5/0.25/50 (Barr Associates) \\
\hline & Liquid water/403.2/6.0/50 (Barr Associates) \\
\hline & Nitrogen/386.68/0.1/60 (Barr Associates) \\
\hline & $\begin{array}{l}\text { Oxygen } / 375 / 0.3 \text { or } \mathrm{CO}_{2} / 371.71 / 0.3 / 25 \\
\text { (Barr Associates) }\end{array}$ \\
\hline & $\begin{array}{l}\text { Elastic unpolarized/354.7/0.3/50 (Barr } \\
\text { Associates) }\end{array}$ \\
\hline & $\begin{array}{l}\text { Elastic parallel polarized/354.7/0.3/50 } \\
\text { (Barr Associates) }\end{array}$ \\
\hline & $\begin{array}{l}\text { Elastic perpendicular polarized/354.7/0.3/50 } \\
\text { (Barr Associates) }\end{array}$ \\
\hline Detectors & $\begin{array}{l}\text { Hamamatsu R1924 PMTs; products are for } \\
\text { research bases }\end{array}$ \\
\hline Field of view & $0.25 \mathrm{mrad}$ \\
\hline
\end{tabular}

and average droplet radius were acquired over a period of approximately $25 \mathrm{~min}$ using a 1 -min average for each profile. The retrievals are performed only for a vertical window that is completely inside of the cloud. Therefore, in this case, the bottom and top of the profiles end $90 \mathrm{~m}$ before cloud base or top. An example retrieval from these measurements is shown in Fig. 9. On the left-hand side of Fig. 9 is shown the profile of the cloud backscatter coefficient and cloud liquid water content using the techniques referenced above. A 1-min temporal average was used along with a vertical average of $90 \mathrm{~m}$. On the righthand side of Fig. 9 are shown the corresponding droplet radius and number density retrievals, which indicate an increase in droplet size and a decrease in number density progressing from the bottom of the cloud toward the top. This could be an indication of droplets colliding and fusing together due to updrafts.

The retrievals from all 25 profiles were composited to form the size distribution spectrum shown in Fig. 10. Both the individual RASL retrievals as well as size interval averages are shown. Also plotted for reference are two example size distributions: one from near the top of a developing continental cumulus cloud (Hobbs et al. 1980) and the other for a maritime cumulus cloud (Battan and Reitan 1957). In situ spectra typically represent measurements taken at a single altitude in the cloud as in the case of the developing cumulus cloud 

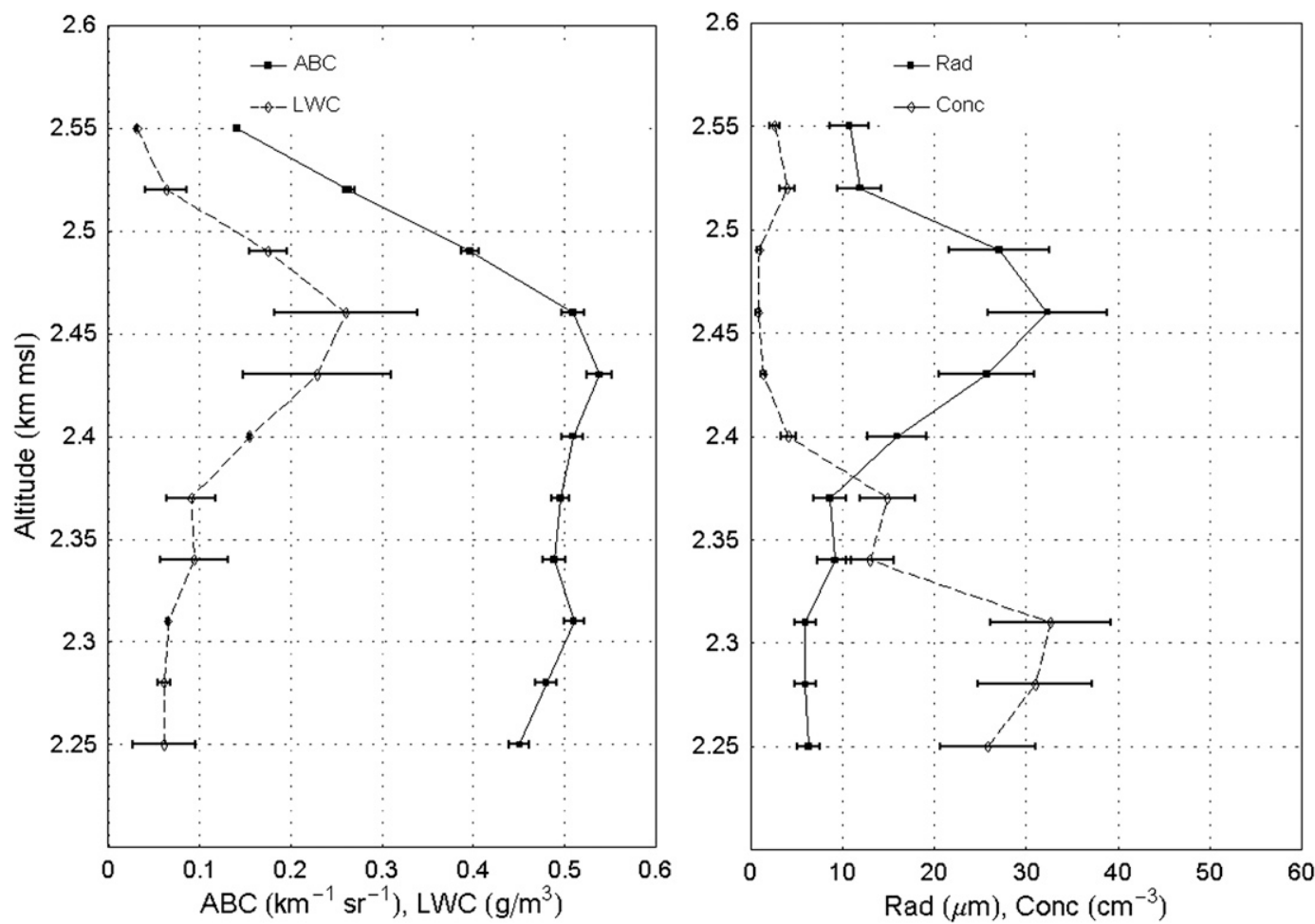

FIG. 9. Profile of (left) the aerosol backscatter coefficient (ABC) and cloud liquid water (LWC); (right) cloud droplet radius (Rad) and number density (Cone) acquired on the night of 3 Jul 2007.

spectrum shown here while the RASL spectrum reflects the entire profile. Within these limitations, the comparison shown in Fig. 10 indicates that the RASL-derived spectrum qualitatively exhibits characteristics of both of the other spectra shown. The small droplet portion of the RASL spectrum is similar to the developing cumulus spectrum shown while the large droplet portion of the RASL spectrum resembles more the maritime cumulus spectrum. Although the comparisons of RASL droplet size spectrum with those from the literature are encouraging, validation of the RASL retrieval capability would require simultaneous in situ measurements during a RASL overflight.

\section{6) CARBon DIOXIDE}

On the night flight of 3 July, an attempt was made to measure the profile of carbon dioxide using the same RASL experimental configuration as was used by Whiteman et al. (2007). Overflights of the John E. Amos power plant, a coal-fired facility in Winfield, West Virginia, were made both upwind and downwind with the goal of detecting a significant difference in the $\mathrm{CO}_{2}$ profile between the upwind and downwind legs. On this evening, aerosols associated with fires in the midwestern region of the United States were present over the measurement site. We observed what we believe to be a small fluorescence signal in the 371.7-nm RASL channel that contaminated the $\mathrm{CO}_{2}$ measurements. Therefore, no detection of $\mathrm{CO}_{2}$ was possible from these data. The earlier laboratory measurements (Whiteman et al. 2007), by contrast, showed no evidence of aerosol fluorescence. Future attempts to measure $\mathrm{CO}_{2}$ should be made in the absence of smoke aerosols, which, due to the likely presence of complex organics, may possess strong fluorescence.

\section{d. Performance projections for an optimized system}

Following the RASL flight campaign during WAVES_ 2007, the RASL instrumentation was integrated into the mobile trailer that formerly held the SRL (Whiteman et al. 2006a,b). The SRL was decommissioned in 2007 due to severe damage sustained during transportation to a field campaign in 2006. The SRL trailer was refurbished and RASL was installed in an upward-looking configuration known as ALVICE for participation in the MOHAVE-II field campaign, which focused on upper-tropospheric and lower-stratospheric water vapor. The results of that ground-based campaign, which are detailed in section 3, permitted a detailed numerical simulation of the Raman water vapor and nitrogen channel signals. This simulation led to the conclusion that the 0.1-nm-wide interference filter used to measure the RASL Raman $\mathrm{N}_{2}$ signal was incorrectly angle tuned, resulting in approximately a factor 


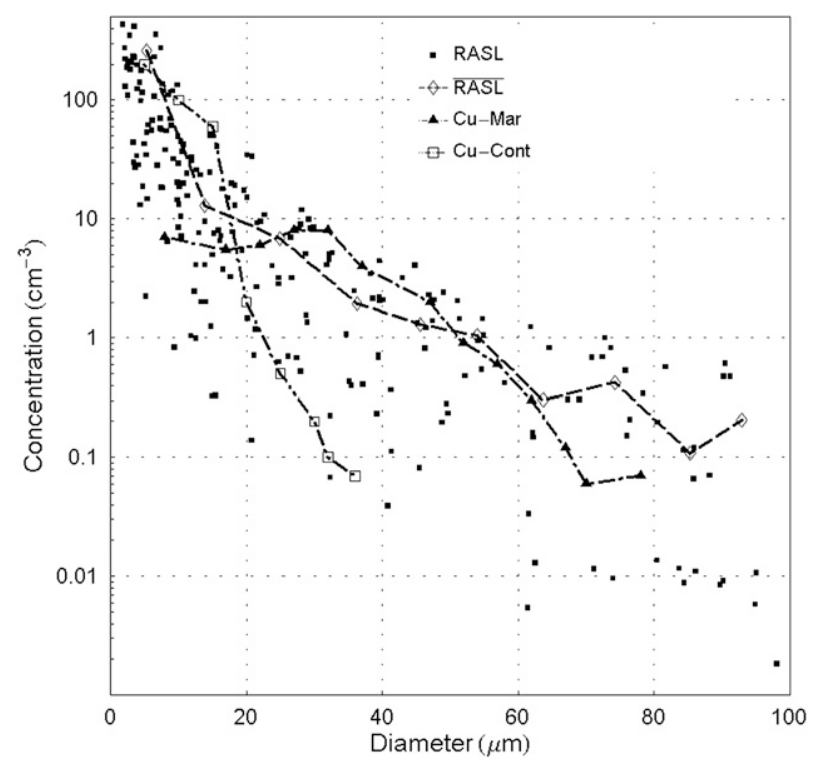

FIG. 10. RASL spectrum of droplet size distribution derived from measurements on $3 \mathrm{Jul} 2007$ compared with other cumulus cloud distributions from the literature.

of 10 decrease in the $\mathrm{N}_{2}$ channel throughput. This factor of 10 decrease in signal is consistent with the decreased aerosol extinction performance discussed in section $2 \mathrm{c}(4)$.

The results presented in section 3, therefore, permit projections of the full RASL performance assuming that full laser power $(17.5 \mathrm{~W})$ is achieved and that the $\mathrm{N}_{2}$ filter is properly tilt tuned. Because of the subaperture use of the RASL telescope, the projections made here are for a $0.5-\mathrm{m}$ telescope instead of the 0.6-m telescope actually installed in the aircraft. The performance projections were made by first using a numerical Raman lidar model (Whiteman et al. 2001b) to match the actual RASL profiles. Model profiles were then generated by changing the inputs to the model for laser power and $\mathrm{N}_{2}$ interference filter transmission to reflect the optimized values. These latter profiles were used to quantify the extrapolated RASL performance shown in Table 2, where averaging times have been increased by $\sim 25 \%$ to be conservative in the projections. Table 2 summarizes 1) the originally predicted measurement performance for various aerosol and water vapor parameters, 2) the demonstrated performance with suboptimal performance from the laser and $\mathrm{N}_{2}$ interference filter and subaperture telescope, and 3) the projected performance under the measurement conditions of 2 July and 3 August 2007 but assuming nominal performance from both the laser and the interference filter while still assuming the use of the subaperture telescope.

\section{e. Discussion of airborne results}

The entries in Table 2 all assume approximately 10\% random error, an 8-km flight altitude, and typical midAtlantic summertime profiles of water vapor and aerosols such as those observed during the RASL flights. The vertical resolutions required to meet the random error specification are also shown in Table 2. For the measurement of the aerosol extinction and extinction-tobackscatter ratio, there is the further assumption that measurements are made within the atmospheric boundary layer. Given these assumptions, the RASL performance projections indicate that water vapor mixing profiles can be made in 5 and $30 \mathrm{~s}$ during the night and day, respectively, assuming no sharp decreases are present in the profile of the water vapor or aerosols. As demonstrated by Fig. 3, sharp decreases can be present in the real atmosphere and in these cases the error budget will increase since the random error in a Raman lidar signal is directly related to the signal strength.

TABLE 2. RASL measurements during WAVES_2007 were made using a suboptimal laser and a Raman nitrogen filter that was mistuned. Numerical simulation was used to account for these performance degrading factors to project the optimized performance shown here. No accounting was made for the subaperture use of the RASL telescope; therefore, these performance projections essentially assume the use of a $0.5-\mathrm{m}$ telescope.

\begin{tabular}{|c|c|c|c|c|c|c|}
\hline \multicolumn{7}{|c|}{ Performance predicted, demonstrated, and projected } \\
\hline Measurement & $\begin{array}{l}\text { Predicted } \\
\text { resolution } \\
\text { (daytime) }\end{array}$ & $\begin{array}{c}\text { Demonstrated } \\
\text { resolution } \\
\text { (daytime) }\end{array}$ & $\begin{array}{l}\text { Projected } \\
\text { resolution } \\
\text { (daytime) }\end{array}$ & $\begin{array}{l}\text { Predicted } \\
\text { resolution } \\
\text { (nighttime) }\end{array}$ & $\begin{array}{l}\text { Demonstrated } \\
\text { resolution } \\
\text { (nighttime) }\end{array}$ & $\begin{array}{l}\text { Projected } \\
\text { resolution } \\
\text { (nighttime) }\end{array}$ \\
\hline $\begin{array}{l}\text { Water vapor } \\
\text { mixing ratio }\end{array}$ & $60-120 \mathrm{~s}, 100-300 \mathrm{~m}$ & $50 \mathrm{~s}, 30-300 \mathrm{~m}$ & $30 \mathrm{~s}, 30-300 \mathrm{~m}$ & $5-10 \mathrm{~s}, 100-300 \mathrm{~m}$ & $10 \mathrm{~s}, 30-270 \mathrm{~m}$ & $5 \mathrm{~s}, 30-270 \mathrm{~m}$ \\
\hline $\begin{array}{l}\text { Aerosol backscatter } \\
\text { coefficient }\end{array}$ & $<10 \mathrm{~s}, 100-200 \mathrm{~m}$ & $5 \mathrm{~s}, 30-150 \mathrm{~m}$ & $3 \mathrm{~s}, 30-150 \mathrm{~m}$ & $<10 \mathrm{~s}, 100-200 \mathrm{~m}$ & $5 \mathrm{~s}, 30-150 \mathrm{~m}$ & $3 \mathrm{~s}, 30-150 \mathrm{~m}$ \\
\hline Aerosol depolarization & $10-60 \mathrm{~s}, 100 \mathrm{~m}$ & $3 \mathrm{~s}, 30-100 \mathrm{~m}$ & $2 \mathrm{~s}, 30-100 \mathrm{~m}$ & $10-60 \mathrm{~s}, 100 \mathrm{~m}$ & $3 \mathrm{~s}, 30-100 \mathrm{~m}$ & $2 \mathrm{~s}, 30-100 \mathrm{~m}$ \\
\hline Aerosol extinction & $60 \mathrm{~s}, 200-300 \mathrm{~m}$ & $\begin{array}{c}210 \mathrm{~s}, 330 \mathrm{~m} \\
\quad(<20 \%)\end{array}$ & $45 \mathrm{~s}, 330 \mathrm{~m}$ & $60 \mathrm{~s}, 200-300 \mathrm{~m}$ & $\begin{array}{c}210 \mathrm{~s}, 330 \mathrm{~m} \\
(<20 \%)\end{array}$ & $45 \mathrm{~s}, 330 \mathrm{~m}$ \\
\hline $\begin{array}{l}\text { Extinction to } \\
\text { backscatter ratio }\end{array}$ & $60 \mathrm{~s}, 200-300 \mathrm{~m}$ & $\begin{array}{c}210 \mathrm{~s}, 330 \mathrm{~m} \\
(<20 \%)\end{array}$ & $45 \mathrm{~s}, 330 \mathrm{~m}$ & $60 \mathrm{~s}, 200-300 \mathrm{~m}$ & $\begin{array}{l}210 \mathrm{~s}, 330 \mathrm{~m} \\
\quad(<20 \%)\end{array}$ & $45 \mathrm{~s}, 330 \mathrm{~m}$ \\
\hline
\end{tabular}


The performance projections for aerosol extinction indicate that profiles with approximately $10 \%$ random error are possible in $45 \mathrm{~s}$ using $330-\mathrm{m}$ vertical smoothing. There is no significant difference between the levels of daytime and nighttime performance due to the use of a $0.1-\mathrm{nm}$ filter, which reduces the background due to skylight to well below the signal levels. Other aerosol parameters can be quantified much more rapidly. Both aerosol depolarization and aerosol backscatter can be measured in 2-3 s. Because of the much lower uncertainty in the aerosol backscatter measurement, the performance projections for the aerosol extinction-to-backscatter ratio are essentially identical to those of the aerosol extinction.

A detailed comparison of the projected RASL performance and that of existing airborne instruments would consider random and systematic error sources as well as calibration methods and other factors. To do so is beyond the intent or scope of this paper. Nonetheless, it is possible to make some simple comparisons with other airborne lidar systems to assess the projected performance of RASL. Numerous airborne water vapor Differential Absorption Lidar (DIAL) systems are in use in atmospheric sciences research. Depending on the measurement altitude, strength of the absorption line, number of absorption lines, laser power, and other parameters, these systems have provided useful profiling of water vapor over various ranges with temporal resolutions ranging from 1-2 s to 2 min (Kiemle et al. 2007; Wulfmeyer et al. 2006; Kamineni et al. 2003; Ferrare et al. 1999). Range resolution has varied from approximately 50 to more than $300 \mathrm{~m}$. The projected RASL water vapor resolution during the nighttime does not match recent high-resolution DIAL water vapor measurements made during the Convective and Orographically-Induced Precipitation Study (COPS; Kiemle et al. 2007). However, both daytime- and nighttime-projected RASL resolutions are better than what has been used successfully by DIAL instruments in other airborne measurement campaigns (Wulfmeyer et al. 2006; Kamineni et al. 2003; Ferrare et al. 1999). In very simple terms, these results are achieved by both maximizing the signal and minimizing the noise in the Raman lidar measurement process (Whiteman et al. 2006a, 2007).

High spectral resolution lidars are now being used in airborne science research. They provide direct quantification of both the aerosol extinction and the extinction-tobackscatter ratio at $532 \mathrm{~nm}$. The temporal resolutions of the published measurements range from 15 to $60 \mathrm{~s}$ with range resolutions of 540 and $300 \mathrm{~m}$ (Esselborn et al. 2008; Hair et al. 2008), respectively. These systems are providing new insights into aerosol composition and transport. Additionally, they offer backscatter and depolarization measurements at $1064 \mathrm{~nm}$, adding significantly to the information content of the measurements. The projected RASL extinction measurements are made at $355 \mathrm{~nm}$ and have roughly comparable resolution to the extinction measurements made by the HSRL instruments at $532 \mathrm{~nm}$.

Since the time of the airborne measurement campaign detailed here, optical channels have been added to the RASL telescope permitting rotational Raman temperature measurements to be made using the 355-nm laser output. The demonstrated performance of these groundbased temperature measurements indicates that airborne temperature profiles with less than $1-\mathrm{K}$ statistical error can be made simultaneously with the other RASL measurements using $15-30 \mathrm{~s}$ of averaging. This will permit relative humidity measurements to also be made simultaneously with those of the aerosol extinction, backscatter, depolarization, and cloud liquid water in the next flights of RASL.

As for the future, it should be noted that the RASL instrument used a flash-lamp-pumped Nd:YAG laser for these demonstration measurements. RASL, as installed in the King Air B200, weighed almost $800 \mathrm{~kg}$ and required approximately $6 \mathrm{~kW}$ of continuous power. Much of the weight and power budgets were due to the laser components themselves, the mechanical hardware to secure them, and the apparatus required to cool them. High-power diode-pumped lasers are now commercially available that would greatly decrease the weight, volume, power, and cooling requirements of an airborne Raman lidar with performance exceeding that of the optimized RASL. For example, Fibertek, Inc., the manufacturer of the laser for the NASA Langley Research Center (LaRC) HSRL airborne lidar (Hair et al. 2008), offers a 50-Hz laser with $480-\mathrm{mJ}$ pulses at $355 \mathrm{~nm}$ for a power output of $24 \mathrm{~W}$ (F. Hovis, Fibertek, 2009, personal communication). This laser weighs much less than the RASL laser (approximately 74 versus $175 \mathrm{~kg}$ ), requires much less power (approximately $700 \mathrm{~W}$ versus $3.5 \mathrm{~kW}$ ) and is thus considerably easier to accommodate in a small research aircraft. The use of such a laser would decrease the averaging times shown in Table 2 by approximately $25 \%$. Furthermore, the subaperture use of the RASL telescope, as demonstrated here, implies that the projected performance is based on the equivalent of a $0.5-\mathrm{m}$ telescope and not the $0.6 \mathrm{~m}$ actually installed. All of these factors taken together indicate that an airborne Raman lidar system with performance exceeding that of the projected RASL performance shown in Table 2, and with the addition of rotational Raman temperature measurements, could be accommodated in a package of less than $500 \mathrm{~kg}$ and require approximately $3 \mathrm{~kW}$ or less of aircraft power. 


\section{Ground-based measurements in support of the Network for the Detection of Atmospheric Composition Change (NDACC)}

The task of quantifying upper-tropospheric and lowerstratospheric water vapor with sufficient accuracy to monitor trends in climate is a substantial challenge. Technologies that are candidates for this task include balloon-borne sensors such as frost-point hygrometers and Lyman-Alpha instruments (Vömel et al. 2007c), as well as satellite measurements such as the Microwave Limb Sounder (MLS; Vömel et al. 2007b) and ground-based instruments such as Raman lidar. The Network for the Detection of Atmospheric Composition Change (NDACC) has recently established the long-term monitoring of water vapor using Raman lidar as one of its core objectives (Leblanc and McDermid 2008). Some of the major activities undertaken to address this objective have occurred at the Table Mountain Facility (TMF) of the Jet Propulsion Laboratories (elevation $2.3 \mathrm{~km}$ ), where a large power-aperture Raman lidar system has been developed for monitoring the water vapor mixing ratio in the upper troposphere and lower stratosphere. A coordinated part of this NDACC effort has been the hosting of intensive field campaigns at the TMF location. These campaigns include the MOHAVE field campaigns (Leblanc and McDermid 2008). A ground-based version of the RASL that was described in section 2 was deployed in a mobile trailer for the second of these MOHAVE campaigns held in October 2007. Here, we describe the level of performance of the ALVICE water vapor mixing ratio demonstrated during that campaign and analysis based on those operations. These results indicate that a Raman lidar system with the specifications of RASL-ALVICE can usefully probe lower-stratospheric water vapor and offer an explanation for the suboptimal aerosol extinction performance of RASL during the WAVES_2007 campaign.

\section{a. ALVICE operations during MOHAVE-II}

ALVICE was deployed to the TMF for the MOHAVE-II campaign in early October 2007. At that time, the hardware configuration of ALVICE was essentially identical to that of the RASL system described above. The main difference between the hardware configuration shown in Table 1 and the configuration of ALVICE for the MOHAVE-II campaign was that a seeded version of the Continuum 9050 laser was used for the MOHAVE campaign.

\section{INSTRUMENT SETUP AND OPTIMIZATION}

At the beginning of the MOHAVE campaign, experiments were performed on the ALVICE hardware in order to optimize the performance of the system. These experiments involved spectrally adjusting (by mechanically tilting) the central wavelength of the Raman $\mathrm{N}_{2}$ filter to maximize the signal throughput, installing a reflective blocker in the system to reduce the magnitude of the 355-nm signal that is transmitted to the Raman channels, and adjusting the $\times 5$ laser beam expander to maximize the far-field signal. Each of these experiments will be briefly described.

\section{(i) Optimizing the Raman $\mathrm{N}_{2}$ filter}

The $\mathrm{N}_{2}$ interference filter used for both the airborne RASL measurements and the ground-based ALVICE measurements described here was developed under a NASA Advanced Component Technology (ACT) research effort involving Barr Associates and our Raman lidar group (Whiteman et al. 2007). One of the interference filters produced during that research was specifically designed to maximize the performance of the Raman $\mathrm{N}_{2}$ measurement and possessed a 0.1-nm full width at half maximum (FWHM) and approximately $60 \%$ peak transmission. The central wavelength was specified to be approximately $0.1 \mathrm{~nm}$ longer than the center of the Raman $\mathrm{N}_{2} \mathrm{Q}$ branch when excited by a tripled $\mathrm{Nd}$ :YAG laser $(\approx 386.7 \mathrm{~nm})$. Specifying the filter with a longer wavelength permits the filter to be tilt tuned to align the transmission peak of the filter with the Raman return signal. The Raman $\mathrm{N}_{2} \mathrm{Q}$ branch, when excited at $354.7 \mathrm{~nm}$, itself covers approximately $0.07-$ $0.08 \mathrm{~nm}$ (Bendsten and Rasmussen 2000) so the use of a filter narrower than $0.1 \mathrm{~nm}$ could lead to a significant reduction in signal throughput. Because the width of the filter used here is only about $0.02 \mathrm{~nm}$ wider than the feature desired to be measured, careful tuning of the transmission peak of the filter is required. Such tuning was not performed during the airborne measurements because of a host of higher-priority items that were being addressed in those first-flight efforts. The MOHAVE campaign provided good operating conditions for performing this tuning through the repeated tilting of the filter and inspection of the return signal strength at far range. The use of a seeded laser simplified the task of maximizing the filter transmission tilt angle since at each candidate tilt angle it was possible to scan the laser output wavelength over a range of approximately $0.03 \mathrm{~nm}$ while monitoring the laser power at each wavelength. The proper centering of the filters transmission peak on the Raman $\mathrm{N}_{2}$ feature was determined by minimizing the change in the received signal strength as a function of the change in laser output wavelength. The signal strength achieved in the Raman $\mathrm{N}_{2}$ channel after these optimizations was compared with the signal strength achieved during the airborne campaign, confirming that the $0.1-\mathrm{nm}$ filter was misaligned by approximately $1.5^{\circ}$ during the 
WAVES_2007 campaign. This misalignment resulted in approximately an order of magnitude reduction in signal strength during the airborne campaign. As a note, the RASL water vapor channel performance appeared to be nominal during the WAVES_2007 campaign and therefore no similar tuning exercises for the water vapor filter were performed during the MOHAVE campaign.

\section{(ii) Use of a reflective blocker}

Two of the lidar systems that participated in the first MOHAVE campaign in 2006 (Leblanc and McDermid 2008) used optical fibers to relay the signal from the prime focus of the telescope to a receiver box that performed the wavelength selection and detection. Fluorescence in these optical fibers was found to contaminate the uppertropospheric water vapor signal even when using "HighOH" fibers as previously recommended (Sherlock et al. 1999). After the conclusion of this first MOHAVE campaign, further investigations were performed on fiber optics that were specifically obtained from manufacturers to minimize fluorescence. All of the fibers tested indicated the presence of fluorescence of significant magnitude when considered within the context of measuring a weak Raman water vapor signal in the UT-LS.

Although most of the attention was focused on the presence of fluorescence in optical fibers, there was still concern over the presence of fluorescence in nonfiber coupled lidar systems like ALVICE. For this reason, a custom reflective blocker, with more than five orders of rejection of the laser fundamental and $>99 \%$ transmission for wavelengths greater than $385 \mathrm{~nm}$, was obtained from Barr Associates with the goal of minimizing the amount of potentially fluorescence-inducing $355-\mathrm{nm}$ light that was transmitted into the Raman section of the ALVICE receiver module. The addition of the reflective blocker itself had no noticeable effect on the measured amount of sky background. However, long-duration measurements made under clear-sky conditions indicated that the addition of this blocker made a noticeable difference in the far-field ALVICE Raman water vapor signal. There was a decrease in the count rate of 1-2 Hz in the region of 25$35 \mathrm{~km}$, consistent with the removal of a small amount of fluorescence.

\section{(iii) Beam expander focusing}

Prior to operations on the night of 10 October, the $\times 5$ laser beam expanding telescope was carefully adjusted to maximize the signal in the far field. A significant increase in the ALVICE far-field water vapor performance was achieved by this adjustment, as can be seen in Fig. 11, which shows the mean water vapor signal count rate (signal + background) using long duration measurements on the nights of 8 October (before the beam

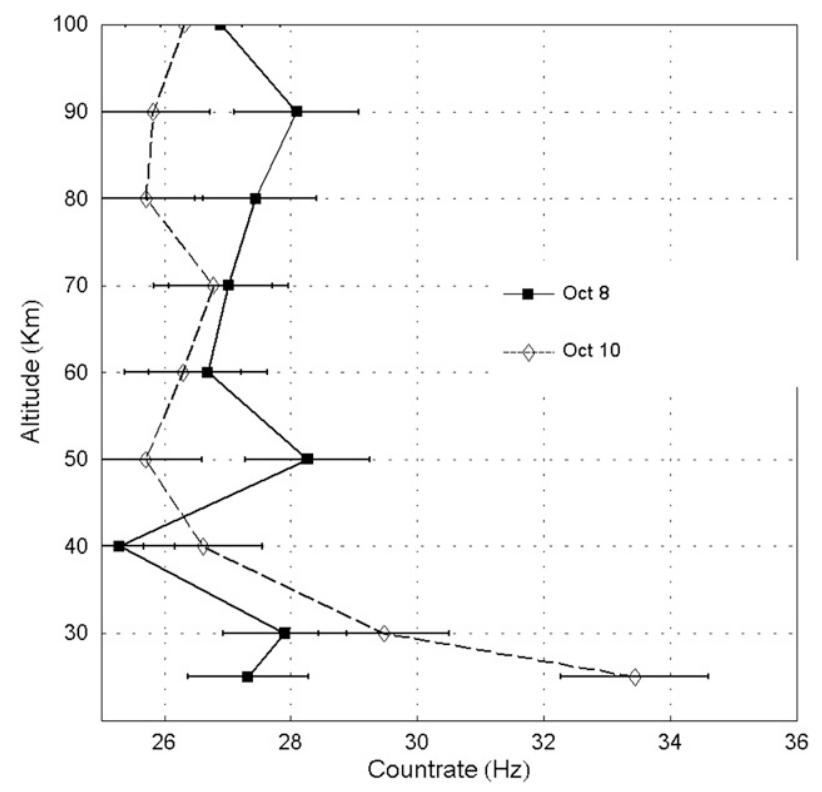

FIG. 11. Water vapor channel count rates measured with longterm averages on the nights of 8 and 10 October. The 8 October measurements were made before optimizing the laser beam expander. The 10 October measurements were made afterward. An increase of 5-6 Hz is apparent in the water vapor signal.

expander adjustment) and 10 October (after the adjustment). At each altitude shown, the value plotted is the average over an interval that spans $\pm 5 \mathrm{~km}$ from the altitude of the point shown. For example, the value shown at $25 \mathrm{~km}$ is an average over the range of $20-30 \mathrm{~km}$. The curves shown are based on approximately $8 \mathrm{~h}$ of data each night. Taking the background count rate to be approximately $26-27 \mathrm{~Hz}$, Fig. 11 shows that the mean signal from water vapor increased by approximately $5-6 \mathrm{~Hz}$ at the 20 $30-\mathrm{km}$ level in the 10 October data and is now clearly discernable as being above the background.

\section{b. Numerical simulations}

The early ALVICE measurements during MOHAVE, such as those from 10 October, indicated significant sensitivity to lower-stratospheric water vapor concentration. As the RASL-ALVICE system had been developed for downward-looking airborne use, no work had been done previously in simulating the expected upward-looking performance under the conditions of the MOHAVE campaign. Therefore, one of the early efforts following MOHAVE was to assess through the use of numerical simulation whether one could expect that a Raman lidar system with the performance parameters of ALVICE could be expected to measure lower-stratospheric water vapor concentrations. Were real signals truly expected to be measured at altitudes beyond $20 \mathrm{~km}$ AGL from a location like Table Mountain as indicated in Fig. 11? 

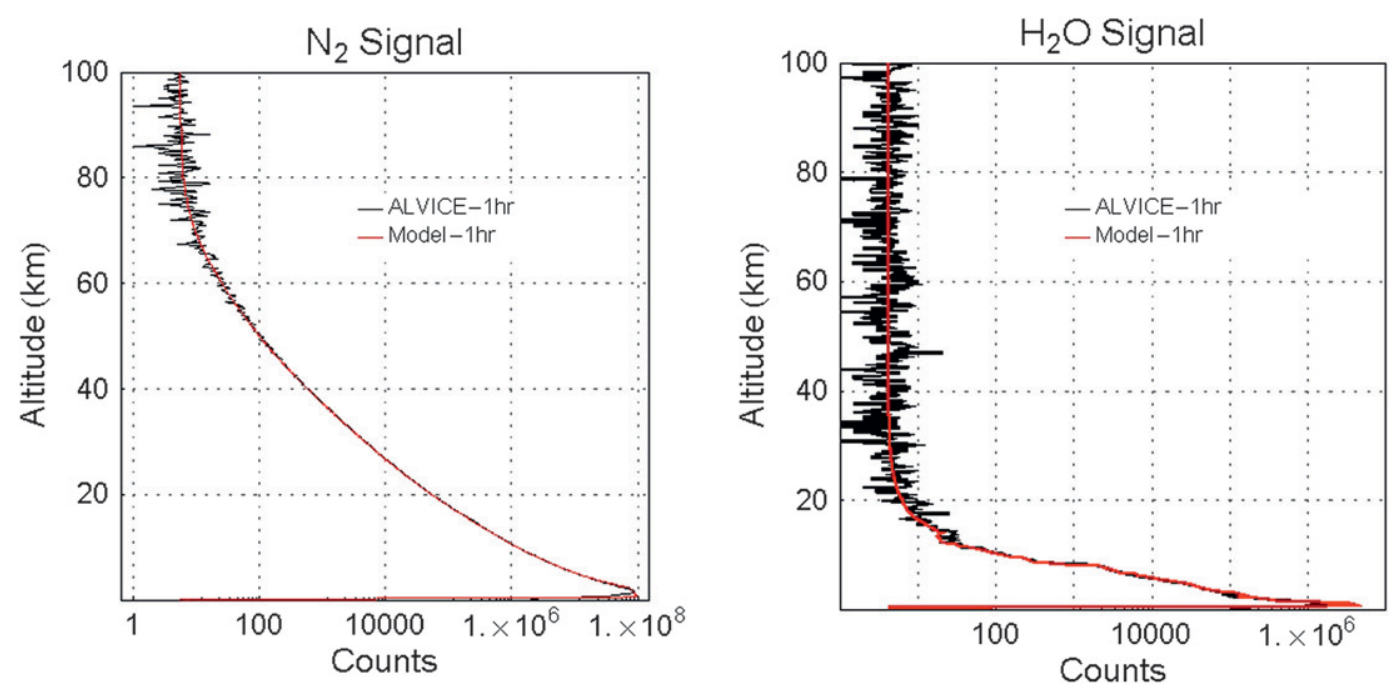

FIG. 12. Comparison of ALVICE (left) nitrogen and (right) water vapor measurements with a numerical simulation of the performance of ALVICE for the night of 14 Oct. The model simulations were performed without random noise so that they can be distinguished more easily from the ALVICE data.

A previously validated numerical model (Whiteman et al. 2001b) was used to address this question using data acquired on the night of 14 October. On this night, two cryogenic frost-point hygrometer (CFH) systems (Vömel et al. 2007a) were launched on balloons during the period of the ALVICE measurements. The CFH data were used to define the water vapor fields that were used as input to the numerical model. Above the maximum altitude of the CFH measurements, U.S. Standard Atmosphere, 1976 data were used to extend the inputs to the model to ranges $>100 \mathrm{~km}$. All known ALVICE efficiency and configuration parameters were also included in the model. For both the water vapor and nitrogen signal simulations, there was a single adjustable efficiency parameter that was used in the model so that the simulated data provided a best fit to the real ALVICE data (Whiteman et al. 2001b). This adjustable parameter accounts for optical efficiencies that are not explicitly provided to the model such as those for telescope and secondary mirror reflectivities and beam splitter and collimating optics transmissions. For this study, a 1-h summation of ALVICE data that began at the time of the CFH launch was used. The values of the free parameters that provided a best fit to the ALVICE data were 0.3 and 0.9 for the nitrogen and water vapor channels, respectively. These values reflect a design goal for RASL of optimizing the water vapor signal throughput in the system at the expense of the nitrogen signal. It also indicates that there is little room for improvement in the water vapor signal throughput of the system. The results of the simulation comparison are shown in Fig. 12, where the model results are presented without random noise so that they appear almost to be an average of the real ALVICE data.

There is very good agreement between the combined analog and photon counting data from ALVICE [the "glued" data; Whiteman et al. (2006a)] and the model simulations. A careful inspection of Fig. 12 reveals that the signal merges into the background at $\sim 80$ and $\sim 30 \mathrm{~km}$ for the nitrogen and water vapor signals, respectively. This model simulation indicates that real signal is present in the ALVICE water vapor data up to ranges of approximately $30 \mathrm{~km}$. The comparison of the actual CFH and ALVICE measurements from 14 October are shown in Fig. 13 using both 1- and 9-h summations of the ALVICE data. The balloon that carried the CFH aloft burst at an altitude of $19 \mathrm{~km}$. A moving average smoothing was implemented on both lidar profiles using a window size that increased from $30 \mathrm{~m}$ at the surface to $1.2 \mathrm{~km}$ above $12 \mathrm{~km}$. The $1-\mathrm{h}$ ALVICE profile is displayed to $19 \mathrm{~km}$ while the 9-h average profile extends to $24 \mathrm{~km}$. Atmospheric variability during the 9-h measurement period degraded the comparison between the CFH and the 9-h average ALVICE profile below approximately $13 \mathrm{~km}$. In the region below $13 \mathrm{~km}$, the 1-h average ALVICE profile agrees much better with the CFH. The comparison of the two ALVICE profiles shown indicates agreement with the $\mathrm{CFH}$ to be generally within $\pm 10 \%$ throughout the extent of the $\mathrm{CFH}$ profile. A single profile comparison is not sufficient for "validation" of any instrument. That is not the intent of this comparison. Instead, the comparison is provided to demonstrate that, in fact, a system of the performance specifications of ALVICE can indeed measure 

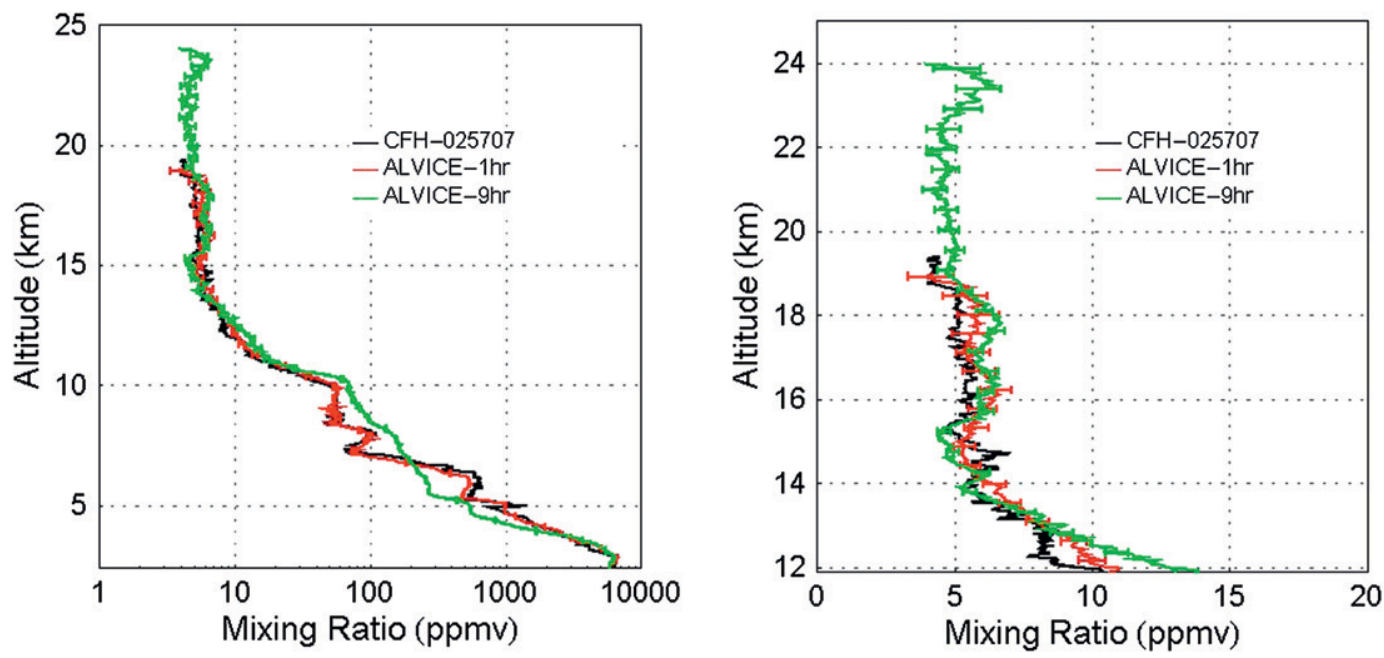

FIG. 13. Comparison of water vapor mixing ratio measurements made by ALVICE and the CFH on the night of 14 Oct 2007. Both 1- and 9-h summations of ALVICE data are shown. The error bars indicate random error assuming Poisson statistics. (right) An expanded view of the data above $12 \mathrm{~km}$.

lower-stratospheric water vapor in a useful manner, substantiating the model predictions.

\section{c. Discussion of ground-based results}

There are a few points to note in considering the measurement of lower-stratospheric water vapor with a Raman lidar. First, as one probes higher and higher toward the tropopause with a Raman lidar located at the surface, the signal is typically decreasing exponentially and the round-trip atmospheric transmission is likewise decreasing exponentially. Considering a range of $15 \mathrm{~km}$ from a surface location at Table Mountain at $2.3 \mathrm{~km}$ and a nearly Rayleigh atmosphere, the round-trip transmission at the Raman water vapor wavelength of $407.5 \mathrm{~nm}$ is approximately 0.45 . For any range beyond $15 \mathrm{~km}$, the decrease in round-trip transmission time is less than an additional $10 \%$. Second, above the cold point in the vicinity of the tropopause, the water vapor concentration assumes a nearly constant or slightly increasing value with range as opposed to the rapid exponential decrease that typically occurs in the troposphere. The combination of these two effects creates, in a certain sense, a "water vapor hurdle" for Raman lidar measurements. If the Raman lidar system can be optimized to measure to ranges of approximately $15 \mathrm{~km}$, then the only remaining significant source of signal decrease with range is the inverse square law, implying that small additional increases in instrument sensitivity can result in much larger improvements in the effective measurement range than at lower altitudes because the "water vapor hurdle" will have been crossed.

The typical approach to improving the performance of a Raman lidar measurement of the water vapor mixing ratio is to increase the "power aperture product" by using a larger telescope or a more powerful laser. One must recall, however, that the measurement challenge under most scenarios involves maximizing the $\mathrm{S} / \mathrm{N}$ in the region of interest. That is certainly the case for Raman lidar measurements of the UT-LS water vapor mixing ratio. The 0.9 value determined for the free efficiency parameter from the ALVICE water vapor channel simulations indicates that significant improvements to the water vapor mixing ratio $\mathrm{S} / \mathrm{N}$ might more easily come through consideration of how to reduce the noise term than how to increase the signal term, as we will now attempt to clarify.

The hardware parameters that are changed in order to increase the signal of a lidar system include the laser power, telescope area, optical efficiency, etc. The parameters that are changed to decrease the noise of the lidar measurement are those that limit either the background signal due to skylight (telescope field of view, interference filter width) or the noise signal due to the detector dark count rate (selection of a different detector or cooling the detector). During the night of 14 October 2007 at Table Mountain, new moon conditions were present. Thus, the amount of skylight was approximately at the minimum expected for this mountaintop location. Nonetheless, the total background count rate found on this night was comprised of approximately $18 \mathrm{~Hz}$ from the photomultiplier detector and $9 \mathrm{~Hz}$ from the sky itself. These values are to be compared with the mean signal count rate between 20 and $30 \mathrm{~km}$ on 10 October shown in Fig. 11 of approximately $6 \mathrm{~Hz}$. Increases in $\mathrm{S} / \mathrm{N}$ at this altitude would be achieved, for example, through the use of a PMT with a lower dark count rate or through cooling the PMT. 
As an example of increasing the $\mathrm{S} / \mathrm{N}$ by focusing on the noise term, consider that the ALVICE water vapor channel $\mathrm{S} / \mathrm{N}$ at the $20-30-\mathrm{km}$ level could be increased by a factor of approximately $2[(6 / 14) \div(6 / 27)]$ if the dark count rate could be reduced from 18 to $5 \mathrm{~Hz}$. Such a decrease in PMT dark count rate is achievable with a careful selection of currently available PMTs or through cooling the PMT. By contrast, to achieve a factor of 2 increase in $\mathrm{S} / \mathrm{N}$ through increasing the power aperture product would be an exceedingly expensive and cumbersome task.

As an alternate way of looking at the optimization challenge, consider a lidar system with the same poweraperture specifications as ALVICE $\left(4.4 \mathrm{~W} \mathrm{~m}^{-2}\right.$ considering laser power, primary mirror and $0.1-\mathrm{m}$ secondary mirror), but with a larger field of view (1.0 mrad versus the $0.25 \mathrm{mrad}$ of ALVICE) and a wider water vapor interference filter $(0.5$ versus $0.25 \mathrm{~nm})$. The increased field of view and interference filter width imply that under the same measurement conditions as were found on 14 October 2007 at Table Mountain the skylight + detector noise background would increase from approximately 27 to $306 \mathrm{~Hz}$ (18 Hz using the same ALVICE detector + $32 \times 9$ for the increase in skylight). The corresponding degradation in $\mathrm{S} / \mathrm{N}$ at the $20-30-\mathrm{km}$ level would be from $6 / 27$ to $6 / 306$, or more than an order of magnitude.

One of the goals of NDACC is to monitor anticipated water vapor trends over the coming decades. The foregoing discussion can lead to the question of what minimum hardware configuration is needed to accomplish this task. Recent work (Boers and Meijgaard 2009; Oman et al. 2008; Soden et al. 2005) indicates that during the current century maximum increases in water vapor mixing ratio can be anticipated to occur in the upper troposphere between 200 and $300 \mathrm{hPa}$ (approximately 9-12-km altitude at TMF), with as much as a doubling of water vapor concentration to be expected in the lowerlatitude regions. In the lower stratosphere, by comparison, modeling has indicated increases of up to $20 \%-40 \%$ (Eyring et al. 2007; Oman et al. 2008) during the same time period. The Raman lidar model used to generate Fig. 12 indicates that a Raman lidar system with 0.4-m telescope, 180 -mJ laser operating at $10 \mathrm{~Hz}, 0.25$-mrad field of view, and $0.25-\mathrm{nm}$ water vapor interference filter, located at the altitude of Table Mountain, California, would be able to measure with $10 \%$ uncertainty to altitudes in excess of $12 \mathrm{~km}$ in a 2-h period. Such a modest system could contribute to monitoring the changes in water vapor in the regions of the atmosphere where the maximum changes are anticipated and do so for a modest hardware investment. The major effort involved in monitoring water vapor trends with Raman lidar, therefore, might not be in developing hardware that has sufficient sensitivity to make the measurements at altitudes where they are needed but rather in maintaining a calibration with sufficient stability over time (Leblanc and McDermid 2008) to create a quality dataset.

\section{Conclusions}

This paper has discussed the use of a single Raman lidar instrument for both ground-based and airborne measurements. The first simultaneous airborne lidar measurements of water vapor mixing ratio and aerosol extinction are presented. While only preliminary data processing was supported for the airborne measurements shown, the test fights studied here demonstrate that an airborne Raman lidar with the hardware specifications of RASL is capable of water vapor and aerosol extinction measurements comparable to other lidar instruments that have been successfully used in meteorological field campaigns and can be flown on a small research aircraft. Furthermore, additional measurements such as aerosol backscattering, depolarization and preliminary retrievals of cloud liquid water, droplet radius, and number density can be made. Rotational Raman temperature retrievals that are now a part of the RASL hardware offer a unique measurement suite for an airborne lidar instrument. The incorporation of a modern diode-pumped Nd:YAG laser into the RASL instrument would permit measurements superior to those projected for the fully operational RASL to be made while significantly decreasing the weight and power requirements of the instrument.

Essentially the same lidar hardware as was flown during the WAVES_2007 field campaign was used during the MOHAVE-II field campaign to demonstrate that a lidar with the performance specifications of RASL can usefully quantify water vapor into the lower stratosphere. The optimization considerations that went into the design of RASL (large-pulse Nd:YAG laser, combined photon counting and analog detection, high-efficiency optics, narrow telescope field of view, narrow bandwidth interference filters) pay significant dividends in quantifying water vapor in the lower stratosphere. The combined airborne and ground-based measurements presented here demonstrate what is likely a unique capability of Raman lidar that would be difficult or impossible to achieve with any other lidar technology.

Acknowledgments. The authors wish to acknowledge the support of the NASA Atmospheric Composition Program, the Advanced Component Technology (ACT) program, the Instrument Incubator Program (IIP), and the Upper Air Research Program (UARP) for support of these efforts. The radiosonde data were obtained from the Howard University Beltsville Research Campus under a program supported by the Maryland Department 
of the Environment. Several individuals have helped in the development of RASL over the years. We wish to thank Geary Schwemmer, Henry Plotkin, Luis RamosIzquierdo, Timothy Berkoff, Glenn Staley, and S. Harvey Melfi. We wish to thank Everette Joseph, Belay Demoz, and the entire Howard University Beltsville Campus staff for hosting the WAVES_2007 campaign. The contributions of T. Leblanc and S. McDermid were carried out at the Jet Propulsion Laboratory, California Institute of Technology, under a contract with NASA. The authors also wish to acknowledge the efforts of Tom McGee, Larry Twigg, and Grant Sumnick during the MOHAVE-II field campaign. The mention of a particular vendor does not constitute an endorsement by NASA.

\section{REFERENCES}

Adam, M., D. Venable, and R. Connell, 2007: Performance of the Howard University Raman lidar during 2006 WAVES campaign. J. Optoelec. Adv. Mater., 9, 3522-3528.

_ , and Coauthors, 2010: Water vapor measurements by Howard University Raman lidar during the WAVES 2006 campaign. J. Atmos. Oceanic Technol., 27, 42-60.

Ansmann, A., M. Riebesell, and C. Weitkamp, 1990: Measurement of atmospheric aerosol extinction profiles with a Raman lidar. Opt. Lett., 15, 746-748.

—, U. Wandinger, M. Riebesell, C. Weitkamp, and W. Michaelis, 1992: Independent measurement of extinction and backscatter profiles in cirrus clouds by using a combined Raman elasticbackscatter lidar. Appl. Opt., 31, 7113-7131.

Battan, L. J., and C. J. Reitan, 1957: Artificial Stimulation of Rain. Pergamon Press, 184 pp.

Behrendt, A., and T. Nakamura, 2002: Calculation of the calibration constant of polarization lidar and its dependency on atmospheric temperature. Opt. Express, 10, 805-817.

— measured with lidar during IHOP_2002. Part I: Airborne to ground-based lidar systems and comparisons with chilled-mirror hygrometer radiosondes. J. Atmos. Oceanic Technol., 24, 3-21.

Bendsten, J., and F. Rasmussen, 2000: High-resolution incoherent Fourier transform Raman spectrum of the fundamental band of ${ }^{14} \mathrm{~N}_{2}$. J. Raman Spectrosc., 31, 433-438.

Boers, R., and E. Meijgaard, 2009: What are the demands on an observational program to detect trends in upper tropospheric water vapor anticipated in the 21st century? Geophys. Res. Lett., 36, L19806, doi:10.1029/2009GL040044.

Bukin, O. A., U. Kh. Kopvillem, S. Yu. Stol-yarchuk, and V. A. Tyapkin, 1983: Investigation of Raman spectra of atmospheric gases. Zh. Prikkadnoi Spektrosk., 38, 776-779.

Burris, J., W. Heaps, B. Gary, W. Hoegy, L. Lait, T. McGee, M. Gross, and U. Singh, 1998: Lidar temperature measurements during the Tropical Ozone Transport Experiment (TOTE)/Vortex OzoneTransport Experiment (VOTE) mission. J. Geophys. Res., 103 (D3), 3505-3510.

— ments from the airborne Raman ozone temperature and aerosol lidar during SOLVE. J. Geophys. Res., 107, 8286, doi:10.1029/ 2001JD001028.

Demoz, B., and Coauthors, 2006: The dryline on 22 May 2002 during IHOP-2002: Convective-scale measurements at the profiling site. Mon. Wea. Rev., 134, 294-310.
Di Girolamo, P., R. Marchese, D. N. Whiteman, and B. B. Demoz, 2004: Rotational Raman lidar measurements of atmospheric temperature in the UV. Geophys. Res. Lett., 31, L01106, doi:10.1029/2003GL018342.

Esselborn, M., M. Wirth, A. Fix, M. Tesche, and G. Ehret, 2008: Airborne high spectral resolution lidar for measuring aerosol extinction and backscatter coefficients. Appl. Opt., 47, 346-358.

Eyring, V., and Coauthors, 2007: Multimodel projections of stratospheric ozone in the 21st century. J. Geophys. Res., 112, D16303, doi:10.1029/2006JD008332.

Ferrare, R. A., and Coauthors, 1999: LASE measurements of water vapor, aerosols, and clouds during CAMEX-3. Proc. Optical Remote Sensing of the Atmosphere, Santa Barbara, CA, Optical Society of America, RWC16.

— - and Coauthors, 2006: Evaluation of daytime measurements of aerosols and water vapor made by an operational Raman lidar over the Southern Great Plains. J. Geophys. Res., 111, D05S08, doi:10.1029/2005JD005836.

Hair, J. W., and Coauthors, 2008: Airborne high spectral resolution lidar for profiling aerosol optical properties. Appl. Opt., 47, 6734-6753.

Harms, J., W. Lahmann, and C. Weitkamp, 1978: Geometrical compression of lidar return signals. Appl. Opt., 17, 1131-1135.

Heaps, W. S., and J. Burris, 1996: Airborne Raman lidar. Appl. Opt., 35, 7128-7135.

Hobbs, P. V., M. K. Politovich, and L. F. Radke, 1980: The structures of summer convective clouds in eastern Montana. I: Natural clouds. J. Appl. Meteor., 19, 645-663.

Inaba, H., and T. Kobayashi, 1972: Laser-Raman radar. OptoElectron., 4, 101-123.

Kamineni, R., T. N. Krishnamurti, R. A. Ferrare, S. Ismail, and E. V. Browell, 2003: Impact of high resolution water vapor cross-sectional data on hurricane forecasting. Geophy. Res. Lett., 30, 1234, doi:10.1029/2002GL016741.

Kiemle, C., M. Wirth, A. Schäfler, A. Fix, S. Rahm, A. Dörnbrack, and G. Ehret, 2007: Water vapour and wind profiles from collocated airborne lidars during COPS 2007. Lidar Technologies, Techniques, and Measurements for Atmospheric Remote Sensing III, U. N. Singh and G. Pappalardo, Eds., International Society for Optical Engineering (SPIE Proceedings, Vol. 6750), 67500P, doi:10.1117/12.737931.

Leblanc, T., and I. S. McDermid, 2008: Accuracy of Raman lidar water vapor calibration and its applicability to long-term measurements. Appl. Opt., 47, 5592-5603.

Melfi, S. H., D. N. Whiteman, and R. A. Ferrare, 1989: Observation of atmospheric fronts using Raman lidar moisture measurements. J. Appl. Meteor., 28, 789-806.

—, K. D. Evans, J. Li, D. Whiteman, R. Ferrare, and G. Schwemmer, 1997: Observation of Raman scattering by cloud droplets in the atmosphere. Appl. Opt., 36, 3551-3559.

Oman, L., D. Waugh, S. Pawson, R. Stolarski, and J. Nielsen, 2008: Understanding the changes of stratospheric water vapor in coupled chemistry-climate model simulations. J. Atmos. Sci., 65, 3278-3291.

Poberaj, G., A. Fix, A. Assion, M. Wirth, C. Kiemle, and G. Ehret, 2002: Airborne all-solid-state DIAL for water vapour measurements in the tropopause region: System description and assessment of accuracy. Appl. Phys., 75B, 165-172.

Reichardt, J., S. Reichardt, A. Behrendt, and T. J. McGee, 2002: Correlations among the optical properties of cirrus-cloud particles: Implications for spaceborne remote sensing. Geophys. Res. Lett., 29, 1029-1032. 
Rizi, V., M. Iarlori, G. Rocci, and G. Visconti, 2004: Raman lidar observations of cloud liquid water. Appl. Opt., 43, 6440-6453.

Russo, F., 2007: An investigation of Raman lidar aerosol measurements and their application to the study of the aerosol indirect effect. Ph.D. dissertation, University of Maryland, Baltimore County, 209 pp.

Sherlock, V., A. Garnier, A. Hauchecorne, and P. Keckhut, 1999: Implementation and validation of a Raman lidar measurement of middle and upper tropospheric water vapor. Appl. Opt., 38, 5838-5850.

Slusher, R. B., and V. E. Derr, 1975: Temperature dependence and cross sections of some Stokes and anti-Stokes Raman lines in Ice Ih. Appl. Opt., 14, 2116-2120.

Soden, B. J., D. L. Jackson, V. Ramaswamy, M. D. Schwarzkopf, and X. Huang, 2005: The radiative signature of upper tropospheric moistening. Science, 310, 841-844.

Veselovskii, I. A., H. K. Cha, D. H. Kim, S. C. Choi, and J. M. Lee, 2000: Raman lidar for the study of liquid water and water vapor in the troposphere. Appl. Phys., 71B, 113-117.

Vömel, H., D. E. David, and K. Smith, 2007a: Accuracy of tropospheric and stratospheric water vapor measurements by the cryogenic frost point hygrometer: Instrumental details and observations. J. Geophys. Res., 112, D08305, doi:10.1029/ 2006JD007224.

— and Coauthors, 2007b: Validation of Aura Microwave Limb Sounder water vapor by balloonborne cryogenic frost point hygrometer measurements. J. Geophys. Res., 112, D24S37, doi:10.1029/2007JD008698.

_ , V. Yushkov, S. Khaykin, L. Korshunov, E. Kyrö, and R. Kivi, 2007c: Intercomparisons of sratospheric water vapor sensors: FLASH-B and NOAA/CMDL frost-point hygrometer. J. Atmos. Oceanic Technol., 24, 941-952.

Wang, Z., D. N. Whiteman, B. B. Demoz, and I. Veselovskii, 2004: A new way to measure cirrus cloud ice water content by using ice Raman scatter with Raman lidar. Geophys. Res. Lett., 31, L15101, doi:10.1029/2004GL020004.

Weber, A., 1979: Raman Spectroscopy of Gases and Liquids. Topics in Current Physics, Vol. 11, Springer-Verlag, 318 pp.
Whiteman, D. N., and S. H. Melfi, 1999: Cloud liquid water, mean droplet radius and number density measurements using a Raman lidar. J. Geophys. Res., 104, 31 411-31 419.

— _ - and R. A. Ferrare, 1992: Raman lidar system for the measurement of water vapor and aerosols in the earth's atmosphere. Appl. Opt., 31, 3068-3082.

— , and Coauthors, 2001a: Raman lidar measurements of water vapor and cirrus clouds during the passage of Hurricane Bonnie. J. Geophys. Res., 106, 5211-5225.

—, G. Schwemmer, T. Berkoff, H. Plotkin, L. Ramos-Izquierdo, and G. Pappalardo, 2001b: Performance modeling of an airborne Raman water vapor lidar. Appl. Opt., 40, 375390.

— B. Bemoz, and Z. Wang, 2004: Subtropical cirrus cloud extinction to backscatter ratios measured by Raman lidar during CAMEX-3. Geophys. Res. Lett., 31, L12105, doi:10.1029/ 2004GL020003.

_ - and Coauthors, 2006a: Raman water vapor lidar measurements during the International $\mathrm{H}_{2} \mathrm{O}$ Project. Part I: Instrumentation and analysis techniques. J. Atmos. Oceanic Technol., 23, 157-169.

— , and Coauthors, 2006b: Raman water vapor lidar measurements during the International $\mathrm{H}_{2} \mathrm{O}$ Project. Part II: Instrument comparisons and case studies. J. Atmos. Oceanic Technol., 23, 170-183.

—, I. Veselovskii, M. Cadirola, K. Rush, J. Comer, J. Potter, and R. Tola, 2007: Demonstration measurements of water vapor, cirrus clouds, and carbon dioxide using a high-performance Raman lidar. J. Atmos. Oceanic Technol., 24, 13771388.

Wulfmeyer, V., H.-S. Bauer, M. Grzeschik, A. Behrendt, F. Vandenberghe, E. V. Browell, S. Ismail, and R. A. Ferrare, 2006: Four-dimensional variational assimilation of water vapor differential absorption lidar data: The first case study within IHOP_2002. Mon. Wea. Rev., 134, 209-230.

Zhang, D.-L., S. Zhang, and S. J. Weaver, 2006: Low-level jets over the mid-Atlantic states: Warm season climatology and a case study. J. Appl. Meteor. Climatol., 45, 194-209. 